\title{
Mitochondrial and Plasma Membrane Potential of Cultured Cerebellar Neurons during Glutamate-Induced Necrosis, Apoptosis, and Tolerance
}

\author{
Manus W. Ward, ${ }^{1 \star}$ Heinrich J. Huber, ${ }^{1,2 \star}$ Petronela Weisová, ${ }^{1}$ Heiko Düssmann, ${ }^{1}$ David G. Nicholls, ${ }^{3}$ and \\ Jochen H. M. Prehn ${ }^{1}$ \\ ${ }^{1}$ Department of Physiology and Medical Physics and RCSI Neuroscience Research Centre, Royal College of Surgeons in Ireland, Dublin 2, Ireland, ${ }^{2}$ Siemens \\ Medical Division, Siemens Ireland, Dublin 2, Ireland, and ${ }^{3}$ Buck Institute for Age Research, Mitochondrial Physiology, Novato, California 94945
}

\begin{abstract}
A failure of mitochondrial bioenergetics has been shown to be closely associated with the onset of apoptotic and necrotic neuronal injury. Here, we developed an automated computational model that interprets the single-cell fluorescence for tetramethylrhodamine methyl ester (TMRM) as a consequence of changes in either $\Delta \Psi_{\mathrm{m}}$ or $\Delta \Psi_{\mathrm{p}}$, thus allowing for the characterization of responses for populations of single cells and subsequent statistical analysis. Necrotic injury triggered by prolonged glutamate excitation resulted in a rapid monophasic or biphasic loss of $\Delta \Psi_{\mathrm{m}}$ that was closely associated with a loss of $\Delta \Psi_{\mathrm{p}}$ and a rapid decrease in neuronal NADPH and ATP levels. Delayed apoptotic injury, induced by transient glutamate excitation, resulted in a small, reversible decrease in TMRM fluorescence, followed by a sustained hyperpolarization of $\Delta \Psi_{\mathrm{m}}$ as confirmed using the $\Delta \Psi_{\mathrm{p}}$-sensitive anionic probe DiBAC ${ }_{2}(3)$. This hyperpolarization of $\Delta \Psi_{\mathrm{m}}$ was closely associated with a significant increase in neuronal glucose uptake, NADPH availability, and ATP levels. Statistical analysis of the changes in $\Delta \Psi_{\mathrm{m}}$ or $\Delta \Psi_{\mathrm{p}}$ at a single-cell level revealed two major correlations; those neurons displaying a more pronounced depolarization of $\Delta \Psi_{\mathrm{p}}$ during the initial phase of glutamate excitation entered apoptosis more rapidly, and neurons that displayed a more pronounced hyperpolarization of $\Delta \Psi_{\mathrm{m}}$ after glutamate excitation survived longer. Indeed, those neurons that were tolerant to transient glutamate excitation (18\%) showed the most significant increases in $\Delta \Psi_{\mathrm{m}}$. Our results indicate that a hyperpolarization of $\Delta \Psi_{\mathrm{m}}$ is associated with increased glucose uptake, NADPH availability, and survival responses during excitotoxic injury.
\end{abstract}

Key words: excitotoxicity; mitochondria; modeling; plasma and mitochondrial membrane potential; bioenergetics; necrosis

\section{Introduction}

Glutamate excitotoxicity is an important contributor to neuronal loss associated with ischemic, traumatic, and seizure-induced brain injury (Choi, 1994). Prolonged glutamate receptor overactivation results in a rapid necrotic neuronal injury that is known to be highly dependent on excessive $\mathrm{Ca}^{2+}$ uptake leading to a loss of mitochondrial bioenergetics, ionic homeostasis, and cellular integrity (Choi, 1987; Tymianski et al., 1993a; Budd and Nicholls, 1996b; White and Reynolds, 1996; Stout et al., 1998; Vergun et al., 1999; Ward et al., 2000). Transient glutamate receptor activation, in contrast, can trigger a delayed apoptotic neuronal injury characterized by nuclear condensation, cell shrinkage, and a delayed collapse of mitochondrial bioenergetics and $\mathrm{Ca}^{2+}$ homeostasis hours after the initial excitation (Ankarcrona et al., 1995; Budd et

\footnotetext{
Received Feb. 26, 2007; revised June 11, 2007; accepted June 13, 2007.

This work was supported by grants from Science Foundation Ireland (03/RP/B344 to J.H.M.P., and the industrial supplement to this grant for funding to H.J.H.), Siemens Ireland, the Royal College of Surgeons in Ireland Research Committee (RCSI 839 to M.W.W.), and the Irish Health Research Board (HRB RP 181/2006 to M.W.W.). We thank Helena Bonner for technical assistance.

${ }^{*} M$.W.W. and H.J.H. contributed equally to this work.

Correspondence should be addressed to Dr. Jochen H. M. Prehn, Department of Physiology and Medical Physics, Royal College of Surgeons in Ireland, 123 St. Stephen's Green, Dublin 2, Ireland. E-mail: prehn@rcsi.ie. DOI:10.1523/JNEUROSCI.1984-07.2007

Copyright $\odot 2007$ Society for Neuroscience $\quad$ 0270-6474/07/278238-12\$15.00/0
}

al., 2000; Luetjens et al., 2000; Ward et al., 2000, 2006). The sequestration of $\mathrm{Ca}^{2+}$ within the mitochondrial matrix has been reported to play an integral role in excitotoxic injury (Budd and Nicholls, 1996b; Wang and Thayer, 1996; White and Reynolds, 1997; Stout et al., 1998; Brocard et al., 2001; Ward et al., 2005), resulting in an early impairment of mitochondrial ADP phosphorylation (Kushnareva et al., 2005).

The mitochondrial membrane potential $\left(\Delta \Psi_{\mathrm{m}}\right)$ is the central parameter controlling the accumulation of $\mathrm{Ca}^{2+}$ within the mitochondrial matrix, respiration, and ATP synthesis (Nicholls and Ferguson, 1992; Nicholls and Budd, 2000; Nicholls, 2002). The fluorescent membrane-permeant cationic probe tetramethylrhodamine methyl ester (TMRM) has become one of the most frequently used probes in the analysis of $\Delta \Psi_{\mathrm{m}}$ in intact cells because of its minimal phototoxicity, low photobleaching, and the ability to use it in both a quenched (aggregated probe) and nonquenched (no aggregation of probe) mode (Ehrenberg et al., 1988; Nicholls and Ward, 2000; Buckman et al., 2001; Gerencser and Adam-Vizi, 2005). Previously, we have successfully used TMRM in the quenched mode to monitor mitochondrial function during glutamate-induced injury in cerebellar granule neurons (Ward et al., 2000) identifying a sensitivity of TMRM to changes in $\Delta \Psi_{\mathrm{m}}$ and the plasma membrane potential $\left(\Delta \Psi_{\mathrm{p}}\right)$. Indeed, the relative contribution of key changes in $\Delta \Psi_{\mathrm{m}}$ and $\Delta \Psi_{\mathrm{p}}$ 
after glutamate excitation have previously been difficult to define (Ankarcrona et al., 1995; Khodorov et al., 1996; White and Reynolds, 1996; Kiedrowski, 1998; Prehn, 1998; Stout et al., 1998; Keelan et al., 1999; Nicholls and Ward, 2000). In this study, we set out to investigate the complex changes that occur at the $\Delta \Psi_{\mathrm{m}}$ and $\Delta \Psi_{\mathrm{p}}$ level in relation to changes in neuronal metabolism and define how alterations in these parameters correlate with neuronal injury and survival after glutamate excitation. We have expanded on a computational model for interpreting whole-cell TMRM fluorescence (Ward et al., 2000; Nicholls, 2006) allowing for the rapid, automated, and impartial assessment of changes in $\Delta \Psi_{\mathrm{m}}$ and $\Delta \Psi_{\mathrm{p}}$ at a single-cell level and subsequent statistical analysis. From this, we have identified significant alterations in $\Delta \Psi_{\mathrm{m}}$ and $\Delta \Psi_{\mathrm{p}}$ that are paralleled with key modifications to neuronal metabolism that directly relate to neuronal outcome (necrosis, apoptosis, and tolerance) after glutamate excitation.

\section{Materials and Methods}

Materials. Fetal calf serum and minimal essential medium were from Invitrogen (Paisley, Strathclyde, UK). Glutamate, glycine, and all other reagents were from Sigma (Poole, Dorset, UK). Fluo-4 AM, $\operatorname{DiBAC}_{2}(3)$, and TMRM were purchased from Invitrogen (Bio Sciences, Dun Laoghaire, Ireland).

Preparation of primary cerebellar granule neurons. Cerebellar granule neurons were prepared as described previously (Ward et al., 2000) with minor modifications. Cerebella from 7-d-old Wistar rats of both sexes were dissected and pooled. The tissue was placed in $20 \mathrm{ml}$ of filter sterilized PBS supplemented with $0.25 \mathrm{mg} / \mathrm{ml}$ trypsin and incubated at $37^{\circ} \mathrm{C}$ for $20 \mathrm{~min}$. Trypsinization was terminated by the addition of an equal volume of filter-sterilized PBS supplemented with $0.05 \mathrm{mg} / \mathrm{ml}$ soybean trypsin inhibitor, $3 \mathrm{mM} \mathrm{MgSO}_{4}$, and $30 \mathrm{U} / \mathrm{ml}$ DNase I. The neurons were then triturated, and the resulting neurons were resuspended in supplemented culture medium. Cells were then plated on poly-L-lysine-coated glass coverslips, glass Willco (Amsterdam, The Netherlands) dishes, 6-well plates, and 24 -well plates at $1 \times 10^{6}$ cells per milliliter and maintained at $37^{\circ} \mathrm{C}$ in a humidified atmosphere of $5 \% \mathrm{CO}_{2} / 95 \%$ air.

Confocal microscopy. Cerebellar granule neurons on Willco dishes were loaded with TMRM ( $30 \mathrm{nM}$ ) only or coloaded with Fluo-4 AM (3 $\mu \mathrm{M}$ ) for $30 \mathrm{~min}$ at $37^{\circ} \mathrm{C}$ (in the dark) in experimental buffer [containing (in $\mathrm{mm}$ ) $120 \mathrm{NaCl}, 3.5 \mathrm{KCl}, 0.4 \mathrm{KH}_{2} \mathrm{PO}_{4}, 202$-[(2-hydroxy-1,1bis(hydroxymethyl)ethyl)amino] ethanesulfonic acid $N$-[Tris(hydroxymethyl)methyl]-2-aminoethanosulfonic acid (Tes), $5 \mathrm{NaHCO}_{3}, 1.2$ $\mathrm{Na}_{2} \mathrm{SO}_{4}, 1.2 \mathrm{CaCl}_{2}, 1.2 \mathrm{MgCl}_{2}$, and 15 glucose, $\mathrm{pH}$ 7.4]. The Willco dishes with cells were washed in fresh medium after loading before being mounted in a nonperfusion $\left(37^{\circ} \mathrm{C}\right)$ holder and placed on the stage of an LSM 510 Meta Zeiss (Oberkochen, Germany) confocal microscope. No $\mathrm{MgCl}_{2}$ was present in buffers for experiments that involved the addition of glutamate. For glutamate-induced apoptosis, neurons were exposed to glutamate and glycine $(100$ and $10 \mu \mathrm{M})$ for $5 \mathrm{~min}$, and (+)-5-methyl10,11-dihydro-5 $\mathrm{H}$-dibenzo[a,d]cyclohepten-5,10-imine maleate (MK$801 ; 10 \mu \mathrm{M}$; Sigma) and 2,3-dioxo-6-nitro-1,2,3,4-tetrahydrobenzoquinoxaline-7-sulfonoamide (NBQX; $10 \mu \mathrm{M}$; Sigma) were added to block glutamate receptor activation. In the model of glutamate-induced necrosis, MK- 801 and NBQX were not added. Fluo- 4 AM was excited at $488 \mathrm{~nm}$ with an argon laser (1\%), and the emission was collected through a 505-550 $\mathrm{nm}$ barrier filter; TMRM was excited at $543 \mathrm{~nm}$ with a helium neon laser (3\%), and the emission was collected through a $560 \mathrm{~nm}$ longpass filter. Images were collected at $15 \mathrm{~s}$ intervals during glutamate excitation and every 5 min during the rest of the experiment, and the resulting fluorescent images were processed using MetaMorph Software version 7.1, release 3 (Molecular Devices, Berkshire, UK).

$\operatorname{DiBAC}_{2}(3)$ is a fluorescent probe that has been successfully used to characterize changes in $\Delta \Psi_{\mathrm{p}}$ (Freedman and Novak, 1989). Here, cerebellar granule neurons were incubated with an experimental buffer containing $1 \mu \mathrm{M} \mathrm{DiBAC}{ }_{2}(3)$ for $30 \mathrm{~min}$ at $37^{\circ} \mathrm{C}$. A concentration of $1 \mu \mathrm{M}$ $\operatorname{DiBAC}_{2}(3)$ was also present in the experimental buffer. $\operatorname{DiBAC}_{2}(3)$ is a bis-barbituric acid oxonol compound that partitions into the membrane as a function of membrane potential. Hyperpolarization causes extrusion of the dye and decreased fluorescence, whereas depolarization causes enhanced fluorescence. Fluorescence was monitored with an LSM 510 (Zeiss) confocal microscope. The probe was excited at $488 \mathrm{~nm}$ with an argon laser (1\%), and the emission was collected through a $530-600 \mathrm{~nm}$ barrier filter. Images were collected at $15 \mathrm{~s}$ intervals during additions [glutamate, oligomycin, carbonyl cyanide p-(trifluoromethoxy) phenylhydrazone (FCCP)] and every 2 min throughout the rest of the experiment. The resulting fluorescent images were processed using MetaMorph software.

Computational modeling. We have used MATLAB software (version 7.0; Mathworks, Cambridge, UK) for the creation of an automated computational model for the analysis of single-cell fluorescence responses for monovalent cationic probes [TMRM, tetramethylrhodamine ethyl ester (TMRE), rhodamine-123] in populations of cells providing rapid predictive output on changes in $\Delta \Psi_{\mathrm{p}}$ and $\Delta \Psi_{\mathrm{m}}$ for large data sets. Previous models have been restricted by the manual fitting of parameters, limited flexibility within the parameters, and low throughput of data sets. This model provides automated output for large data sets with minimal parameter fitting.

This model, as in previous models (Ward et al., 2000; Nicholls, 2006), was based on the Nernstian equilibration of a generic membranepermeant monovalent cation $\mathrm{c}^{+}$(TMRM, TMRE, rhodamine-123). The equilibration concentration for free $\mathrm{c}^{+}$in the extracellular medium, cytosol, and mitochondrial matrix at $37^{\circ} \mathrm{C}$ results in the relationships described below:

$$
\begin{gathered}
c_{[\text {matrix }]}^{+}=c^{+}{ }_{\text {[cytoplasm }]} \times 10^{-\Delta \psi m / 61.5} \\
c_{[\text {[cytoplasm }]}^{+}=c_{[\text {medium }]}^{+} \times 10^{-\Delta \psi p / 61.5} \\
c_{[\text {matrix }]}^{+}=c^{+}{ }_{[\text {medium }]} \times 10^{-(\Delta \psi m+\psi p) / 61.5},
\end{gathered}
$$

where $\Delta \Psi_{\mathrm{p}}$ and $\Delta \Psi_{\mathrm{m}}$ are the plasma and mitochondrial membrane potentials and the divisor 61.5 is the value (in millivolts) for RT/F $\log (2)$ at $37^{\circ} \mathrm{C}$. Re-equilibration of the cytosolic and extracellular compartment attributable to changes in the potentials of $\Delta \Psi_{\mathrm{p}}$ and $\Delta \Psi_{\mathrm{m}}$ are taken into account by assuming a first-order flux between the extracellular medium and the cytosol:

$$
J_{\text {[cytoplasm }]}=\left(c^{+}{ }_{\text {[cytoplasm,actual] }}-c^{+}{ }_{\text {[cytoplasm,equilibrium }]}\right) k_{\text {kinetic }},
$$

where $k_{\text {kinetic }}$ is a constant proportional to the permeability of the $\mathrm{c}^{+}$ probe across the plasma membrane. The equilibration effects between the mitochondria and the cytosol are assumed as immediate. From this, we obtain the whole-cell fluorescence $f_{[\text {cell }]}$ as the sum of the cytosolic and mitochondrial matrix signals by taking into consideration the distinct behavior attributable to quenching of the fluorescence signal within the mitochondria with the quench threshold concentration $c^{+}{ }_{\text {[quench }]}$ :

$$
\begin{gathered}
c_{[\text {matrix }]}^{+}<c^{+}{ }_{\text {[quench }]} \\
f_{[\text {cell }]}=q \times c^{+}{ }_{[\text {cytoplasm }]} \times V_{[\text {cyto }]}+q \times c^{+}{ }_{[\text {matrix }]} \times V_{[\text {mito }]} \\
c_{[\text {matrix }]}^{+}>c^{+}{ }_{[\text {quench }]} \\
f_{[\text {cell }]}=q \times c^{+}{ }_{[\text {cytoplasm }]} \times V_{[\text {cyto }]}+q \times c^{+}{ }_{[\text {quench }]} \times V_{[\text {mito }]} .
\end{gathered}
$$

Here, $q$ is the quantum yield of the probe with $V_{\text {[cyto] }}$ and $V_{\text {[mito] }}$ denoting the cytosolic and mitochondrial volume.

To provide a more accurate model, we re-evaluated the mitochondrial volume $\left(V_{\text {[mito] }}\right)$ within the neurons as well as the rate constant $k_{\text {kinetic }}$ for TMRM (see Fig. 2) and implemented the model into MATLAB. A Newton routine for fitting the membrane potentials to the experimental fluorescent traces was implemented to avoid the need and bias of manual parameter fitting. The mitochondrial volume within the neurons (6.2 \pm $0.8 \%$ SEM) was determined by using the Zeiss LSM 510 confocal microscope to create high-resolution $z$-stacks $(80 \times 0.2 \mu \mathrm{m}$ steps, $0.8 \mu \mathrm{m}$ optical slice) of TMRM-loaded neurons (see Fig. $2 A$ ). The rate constant 
$k_{\text {kinetic }}$ was determined as $0.008 \mathrm{~s}^{-1}$ by remodeling the redistribution of TMRM after the induction of mitochondrial depolarization by the protonophore FCCP in the presence of oligomycin in both the quenched and unquenched mode (see Fig. $2 B, D$ ). Because of variation in both the kinetic constant and the mitochondrial volume between neurons, we included them into the set of parameters for the subsequent fitting routine with an allowed variation of $0.008 \pm 0.001 \mathrm{~s}^{-1}$ and $6.2 \pm 1.7 \%$, respectively.

Parameter fitting was implemented using the built-in Newton-based root-finding algorithm FITCURVE of MATLAB, allowing for up to 50,000 iterations. To pose biological restrictions on the fits, we assumed a functional behavior for the time course of $\left(\Delta \Psi_{\mathrm{p}}\right)$ and $\left(\Delta \Psi_{\mathrm{m}}\right)$ as given in Figure 1 with parameters subject to fitting within a given range (supplemental Table 1 , available at www.jneurosci.org as supplemental material) (Ward et al., 2000; Dussmann et al., 2003; Nicholls, 2006). For the apoptotic model (Fig. $1 \mathrm{~A}$ ), we assumed an initial depolarization $\left(\Delta \Psi_{\mathrm{p}, \text { initial }}\right)$ of the plasma membrane being present between the onset of glutamate and the addition of MK-801, returning to a higher value $\left(\Delta \Psi_{\mathrm{p}, \text { relax }}\right)[-83 \mathrm{mV}$ (Nicholls, 2006)] rapidly after the addition of the antagonist. Moreover, to render the change of experimental fluorescence, we allowed $\Delta \Psi_{\mathrm{m}}$ to vary to a distinct value $\left(\Delta \Psi_{\mathrm{m}, \max }^{\mathrm{Hyp}}\right)$ at the time of glutamate addition and then to exponentially relax (constant $\left.k_{\text {relax }}\right)$ to a certain rate $\left(\Delta \Psi_{\mathrm{m} \text {, relax }}^{H y p}\right)$. During the collapse of $\Delta \Psi_{\mathrm{m}}$ and the onset of apoptosis, we assumed a variant (ii) of our model allowing for exponential decay of both potentials $\left(k_{\mathrm{m}, D C D}, k_{\mathrm{p}, D C D}\right)$ to a final, remnant value $\left(\Delta \Psi_{\mathrm{p}, \text { final }}, \Delta \Psi_{\mathrm{m}, \text { final }}\right)$ after the onset of injury $\left(t_{D C D}\right)$.

For the monophasic necrotic model (Fig. $1 B)$, we assumed a permanent initial depolarization of the plasma $\left(\Delta \Psi_{\mathrm{p}, \text { final }}\right)$ and mitochondrial membrane $\left(\Delta \Psi_{\mathrm{m}, \text { final }}\right)$ with the decay constants $k_{\mathrm{p} \text {, decay, }} k_{\mathrm{m} \text {, decay }}$, respectively. For the biphasic necrotic model (Fig. 1C), we allowed for a change of the mitochondrial membrane $\left(\Delta \Psi_{\mathrm{m}, \text { relax }}^{\text {Hyp/Dep }}, k_{\mathrm{m}, \text { inc/dec }}\right)$ and a decay of the plasma potential $\left(\Delta \Psi_{\mathrm{p}, \text { relax }}, k_{\mathrm{p}}\right.$,decay $)$ after onset of continuous glutamate lasting and before the decay of both potentials, at the time point of injury $\left(t_{D C D}\right)$.

For computational modeling of the $\mathrm{DiBAC}_{2}(3)$ responses, we assumed the measured fluorescence $F_{\text {initial }}, F_{\text {actual }}(t)$ proportional to the cytosolic concentration of the dye with the Nernstian equation:

$$
c^{+}{ }_{\text {[cytoplasm }]}=c^{+}{ }_{[\text {medium }]} \times 10^{-\Delta \psi p / 61.5} .
$$

We obtained the following:

$$
\Delta \psi_{\mathrm{p}}(t)=\log _{10}\left(F_{\text {initial }} / F_{\text {actual }}(t)\right) \times 61.5+\Delta \psi_{\mathrm{p}, \text { initial }} .
$$

Epi-fluorescence NADPH microscopy. Seven- to 8-d-old cerebellar granule neurons on Willco dishes were loaded with TMRM (30 nM) for 30 min at $37^{\circ} \mathrm{C}$ (in the dark), in experimental buffer. The Willco dishes with cells were washed in fresh medium after loading before being mounted in a nonperfusion $\left(37^{\circ} \mathrm{C}\right)$ holder and placed on the stage of a Zeiss Axiovert 200M microscope. During experiments, cells were treated as described above (see Confocal microscopy). NADPH auto fluorescence as well as TMRM fluorescence was observed using an Axiovert 200M inverted microscope equipped with a $63 \times, 1.4$ numerical aperture oil-immersion objective (Zeiss), dichroic beam splitters, and filter wheels in the excita- tion and emission light path containing the appropriate filter sets (NADPH: excitation, $375 \pm 25 \mathrm{~nm}$; emission, $448 \pm 32 \mathrm{~nm}$; TMRM: excitation, $530 \pm 21 \mathrm{~nm}$; emission, $592 \pm 22 \mathrm{~nm}$; filters and dichroic mirrors were made by Semrock, Rochester, NY). Emission and brightfield images were recorded using a back-illuminated, cooled EM CCD camera (Ixon BV 887-DCS; Andor, Belfast, UK). The imaging setup was controlled by MetaMorph software.

ATP luciferase assays. Cerebellar granule neurons were maintained on poly-D-lysine $(5 \mu \mathrm{g} / \mathrm{ml})$-coated 24 -well plates for $7-8 \mathrm{~d}$ before use. The culturing medium was replaced with an experimental buffer (in mM: 120 $\mathrm{NaCl}, 3.5 \mathrm{KCl}, 0.4 \mathrm{KH}_{2} \mathrm{PO}_{4}, 20 \mathrm{TES}, 5 \mathrm{NaHCO}_{3}, 1.2 \mathrm{Na}_{2} \mathrm{SO}_{4}, 1.2 \mathrm{CaCl}_{2}$, and 15 glucose, $\mathrm{pH} 7.4$ ), and the neurons were excited with glutamate/ glycine for 5 min or continuously $(100$ and $10 \mu \mathrm{M})$ and lysed at the times indicated. In separate experiments, cerebellar granule neurons were exposed to combinations of oligomycin $(2 \mu \mathrm{g} / \mathrm{ml})$, FCCP $(2 \mu \mathrm{M})$, and MK-801 (10 $\mu \mathrm{M})$ and maintained for $30 \mathrm{~min}$ before being lysed. The neurons were lysed using a hypotonic lysis buffer (Tris-acetate buffer, $\mathrm{pH}$ 7.75). Fifty microliters of the sample and $50 \mu \mathrm{l}$ of the luciferin-luciferase reaction kit (ENLITEN ATP Assay System Bioluminescence Detection kit; Promega, Southampton, UK) for ATP were reacted to quantify ATP content. The amount of ATP was determined by a concentration standard curve, and ATP content values were normalized according to the protein concentration for each sample (moles ATP/ $\mu$ g protein). 
A

A single Cerebellar granule Neuron loaded with TMRM $30 \mathrm{nM}$

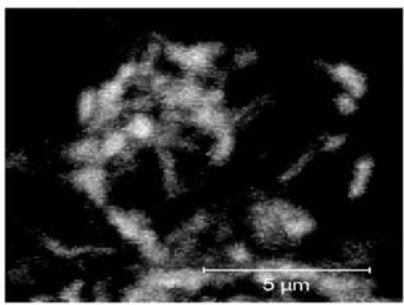

0 degrees rotation
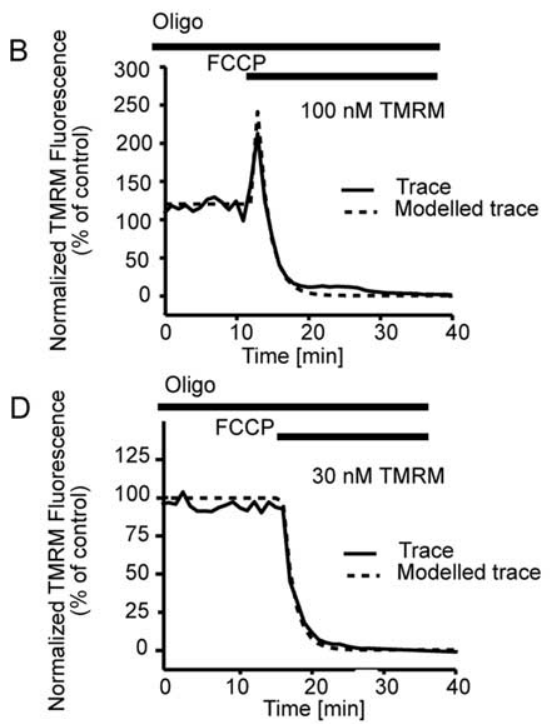

F

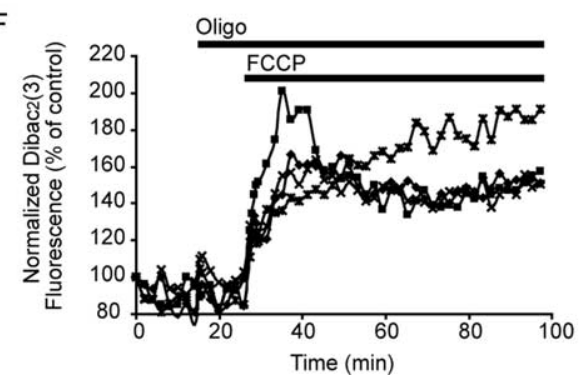

G

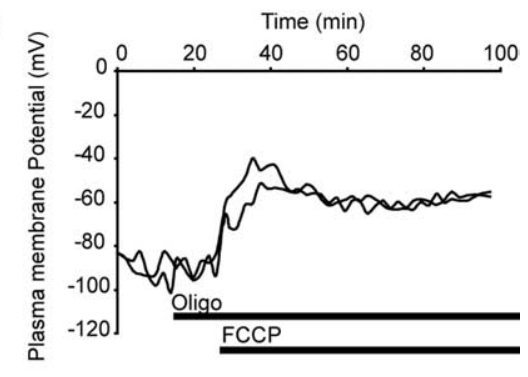

Figure 2. Characterization of TMRM fluorescence in cerebellar granule neurons with high-resolution single-cell confocal microscopy. $\boldsymbol{A}$, Cerebellar granule neurons were loaded with $30 \mathrm{~nm}$ TMRM, and the mitochondrial volume $\left(17.6 \pm 1.5 \mu \mathrm{m}^{3} ; 6.2 \pm\right.$ $0.8 \% ; n=9$ ) was determined by measuring the volume of individual mitochondria within the neurons after the acquisition of high-resolution z-stacks with an LSM 510 confocal microscope. $\boldsymbol{B}, \boldsymbol{D}$, Neurons loaded with $100 \mathrm{~nm}$ TMRM (B) and $30 \mathrm{~nm} \mathrm{TMRM} \mathrm{(D)}$ were exposed to FCCP $(2 \mu \mathrm{m})$ in the presence of oligomycin $(2 \mu \mathrm{g} / \mathrm{ml})$ and monitored over a 60 min period. $C, E$, Using MATLAB software, the traces in $B$ and $D$ were modeled, and the changes in both $\Delta \Psi_{\mathrm{m}}$ and $\Delta \Psi_{\mathrm{p}}$ were established for these control experiments (all experiments were performed 3 times in different cultures). $\boldsymbol{F}$, Cerebellar granule neurons were loaded with the $\Delta \Psi_{\mathrm{p}}$-sensitive probe $\operatorname{DiBAC}_{2}(3)(1 \mu \mathrm{m})$ and exposed to oligomycin $(2 \mu \mathrm{g} / \mathrm{ml})$, followed by FCCP $(2 \mu \mathrm{m})$. A rapid increase in fluorescence (depolarization of $\Delta \Psi_{\mathrm{p}}$ ) was associated with the addition of FCCP (traces are representative of those obtained from 3 separate experiments). $\mathbf{G}$, Representative traces for modeled changes in $\Delta \Psi_{\mathrm{p}}(\boldsymbol{A})$ for neurons exposed to oligomycin $(2 \mu \mathrm{g} / \mathrm{ml})$ and FCCP (2 $\mu \mathrm{m})$. Oligo, Oligomycin.

Glucose uptake assay. Cerebellar granule neurons were maintained on poly-D-lysine ( $5 \mu \mathrm{g} / \mathrm{ml}$ )-coated 96-well plates for 7-8 d before use. The culturing medium was then replaced with an experimental buffer (in mM: $120 \mathrm{NaCl}, 3.5 \mathrm{KCl}, 0.4 \mathrm{KH}_{2} \mathrm{PO}_{4}, 20 \mathrm{TES}, 5 \mathrm{NaHCO}_{3}, 1.2 \mathrm{Na}_{2} \mathrm{SO}_{4}, 1.2$ $\mathrm{CaCl}_{2}$, and 1 glucose, $\mathrm{pH}$ 7.4) minus $\mathrm{MgCl}_{2}$. The cerebellar granule neurons were treated with glutamate/glycine $(100$ and $10 \mu \mathrm{M})$ for $10 \mathrm{~min}$ $\left(37^{\circ} \mathrm{C}\right)$ or exposed to sham conditions (experimental buffer). The excitation buffer was replaced with buffer minus glucose and containing 100 $\mu \mathrm{M} 2$-deoxyglucose and ${ }^{3} \mathrm{H}$-2-deoxyglucose. ${ }^{3} \mathrm{H}$-2-deoxyglucose is taken up by neurons through the glucose transporters; however, it is not fully metabolized by the neuron and is retained within the cell. The neurons were maintained for $20 \mathrm{~min}$ in the experimental buffer containing the ${ }^{3} \mathrm{H}$-2-deoxyglucose; the buffer was then removed, and the neurons were washed twice with cold buffer minus glucose before the addition of $100 \mu$ l of scintillation fluid. The plates were left for 20 min on ice before reading on a Matrix-96 beta counter (Packard, Grove, IL). All conditions were repeated six times per experiment, and the same experiment was performed in at least three different cultures.

Statistics. Data are given as means \pm SEM. For statistical comparison, one-way ANOVA followed by Tukey's test were used. $p$ values $<0.05$ were considered to be statistically significant. Data for $\Delta \Psi_{\mathrm{m}, \Delta} \Psi_{\mathrm{p}}$ and the onset of neuronal injury were plotted using Origin 7 software (OriginLab, Northampton, MA) a linear regression was preformed on the data, and the $R^{2}$ value was calculated for each data set.

\section{Results}

Characterization and computational

modeling of whole-cell TMRM

fluorescence in cerebellar

granule neurons

Cellular TMRM fluorescence is not only highly dependent on the changes in both $\Delta \Psi_{\mathrm{p}}$ and $\Delta \Psi_{\mathrm{m}}$ but is also directly related to the total mitochondrial volume within the cell (Ward et al., 2000; Dussmann et al., 2003; Nicholls, 2006). Therefore, a stringent determination of the mitochondrial volume was performed in cerebellar granule neurons. High-resolution $z$-stacks with $0.2 \mu \mathrm{m}$ steps were taken of three fields of neurons, and the cellular volume $\left(296.9 \pm 32.9 \mu \mathrm{m}^{3}\right)$ and the mitochondrial volume $\left(17.6 \pm 1.5 \mu \mathrm{m}^{3}\right)$ were determined for each neuron (Fig. $2 A$ ). The mitochondrial volume $(6.2 \pm 0.8 \%)$ was found to be larger than that described previously (Ward et al., 2000; Nicholls, 2006)

To determine the rate constant $\left(k_{\text {kinetic }}\right)$ for the redistribution of TMRM, several control experiments were performed (Fig. $2 B, C)$. The protonophore FCCP $(2 \mu \mathrm{M})$ was added to neurons loaded with TMRM in the presence of oligomycin $(2 \mu \mathrm{g} / \mathrm{ml})$ to uncouple $\Delta \Psi_{m}$, and the fluorescent signals were monitored for neurons in both the quenched (Fig. 2B) and nonquenched (Fig. 2D) mode. From the redistribution of the probe after the addition of FCCP, we established a kinetic constant for the redistribution of TMRM of $0.008 \mathrm{~s}^{-1}$.

The MATLAB-based computational model was used to interpret the changes in TMRM fluorescence in response to the addition of FCCP/oligomycin and provide output on changes in $\Delta \Psi_{\mathrm{m}}$ and $\Delta \Psi_{\mathrm{p}}$. Surprisingly, in the modeled traces (Fig. $2 C, E$ ) the expected rapid collapse in $\Delta \Psi_{\mathrm{m}}$ after the addition of FCCP was also closely paralleled with a rapid collapse of $\Delta \Psi_{\mathrm{p}}$. To validate these findings, we 
used the $\Delta \Psi_{\mathrm{p}}$-sensitive fluorescent probe $\operatorname{DiBAC}_{2}(3)$ to monitor changes in $\Delta \Psi_{\mathrm{p}}$ after the addition of oligomycin and FCCP (Fig. $2 F, G)$. A rapid and prolonged increase in $\operatorname{DiBAC}_{2}(3)$ fluorescence after the addition of FCCP that reflected a substantial depolarization of $\Delta \Psi_{\mathrm{p}}$ (Fig. $\left.2 F, G\right)$ was observed.

In addition to monitoring TMRM and $\mathrm{DiBAC}_{2}(3)$ fluorescent responses, changes in $\mathrm{Ca}^{2+}$ dynamics (Fluo-4) and neuronal ATP levels were monitored within the neurons after the addition of FCCP in the presence of oligomycin (Fig. 3). A rapid collapse of $\mathrm{Ca}^{2+}$ homeostasis was identified within the neurons after exposure to the protonophore FCCP (Fig. $3 A$ ). The collapse in $\mathrm{Ca}^{2+}$ homeostasis (Fig. 3A) after the addition of FCCP was completely blocked by the NMDA antagonist MK-801 (Fig. 3B). The addition of oligomycin alone had no significant impact on neuronal ATP levels (Fig. 3); however, oligomycin plus FCCP resulted in a significant decrease $\left({ }^{*} p<0.01\right)$ in ATP levels that was blocked by the presence of the NMDA antagonist MK-801 (Fig. 3C). These results suggest that any $\mathrm{Ca}^{2+}$ entering the neuron is the direct result of NMDA receptor overactivation attributable to glutamate release from the presynaptic terminals. Because the ATP synthase inhibitor oligomycin was present throughout (Fig. 3), energy restrictions alone could not account for the release of glutamate. This is intriguing in that it suggests presynaptic, polarized mitochondria play a key role in the regulation of glutamate within the synapse.

Characterization of $\Delta \Psi_{\mathrm{m}}$ and $\Delta \Psi_{\mathrm{p}}$ during necrotic cell injury induced by prolonged glutamate excitation in cerebellar granule neurons

We have previously characterized a model of excitotoxic necrosis in cerebellar granule neurons induced by prolonged glutamate excitation (Castilho et al., 1998, 1999; Ward et al., 2000). In agreement with previous studies, we identified two major subgroups of neurons after prolonged glutamate excitation: (1) neurons that underwent a rapid collapse of $\Delta \Psi_{\mathrm{m}}(5-20 \mathrm{~min})$ (Fig. $4 A, B)$ with monophasic loss $(33.1 \%)$ of TMRM fluorescence, rapid loss of $\mathrm{Ca}^{2+}$ homeostasis, and neuronal swelling; and (2) neurons that underwent a delayed neuronal injury (15 min to $4 \mathrm{~h}$ ) (Fig. $4 A, B$, ii) with a biphasic drop $(63.4 \%)$ in TMRM fluorescence, a delayed loss of $\mathrm{Ca}^{2+}$ homeostasis, neuronal swelling, and early membrane lysis (Ward et al., 2000; Ward et al., 2005).

From the data obtained (Fig. 4), we used the MATLAB-based computational model (Fig. $1 B, C$ ) for the high throughput assessment of the TMRM fluorescence responses to define potential changes in $\Delta \Psi_{\mathrm{m}}$ and $\Delta \Psi_{\mathrm{p}}$. Representative traces from neurons exposed to glutamate are shown from separate (Fig. 5A,C,E) experiments and modeled output traces for $\Delta \Psi_{\mathrm{m}}$ and $\Delta \Psi_{\mathrm{p}}$ determined for each (Fig. $5 B, D, F$ ): (1) neurons that entered a rapid necrotic cell death with a monophasic decrease in $\Delta \Psi_{\mathrm{m}}$ and $\Delta \Psi_{\mathrm{p}}$ after glutamate excitation (Fig. 5A) and (2) neurons that entered a delayed necrotic injury (Fig. $5 C, E$ ) with a biphasic decrease in $\Delta \Psi_{\mathrm{m}}$ and $\Delta \Psi_{\mathrm{p}}$. The rate at which neurons entered the second phase of injury varied considerably ( $15 \mathrm{~min}$ to $4 \mathrm{~h}$ ) between neurons and cultures; however, all neurons entered a necrotic-like injury with a rapid swelling of the neuron and loss of cellular integrity shortly after the collapse of $\Delta \Psi_{\mathrm{m}}$.

To validate that the modeled $\Delta \Psi_{\mathrm{p}}$ responses above (Fig. $5 B, D, F)$ were accurate, we directly monitored $\Delta \Psi_{\mathrm{p}}$ with the plasma membrane-sensitive probe $\operatorname{DiBAC}_{2}(3)$ (Fig. 4D). Again, two major groups of neurons were identified: neurons that underwent a rapid collapse of $\Delta \Psi_{\mathrm{p}}$ (Fig. $4 D, \mathrm{i}$ ) and neurons that underwent a secondary loss of $\Delta \Psi_{\mathrm{p}}$ (Fig. $4 D$, ii). When the $\mathrm{DiBAC}_{2}(3)$ responses were modeled using the MATLAB software
A

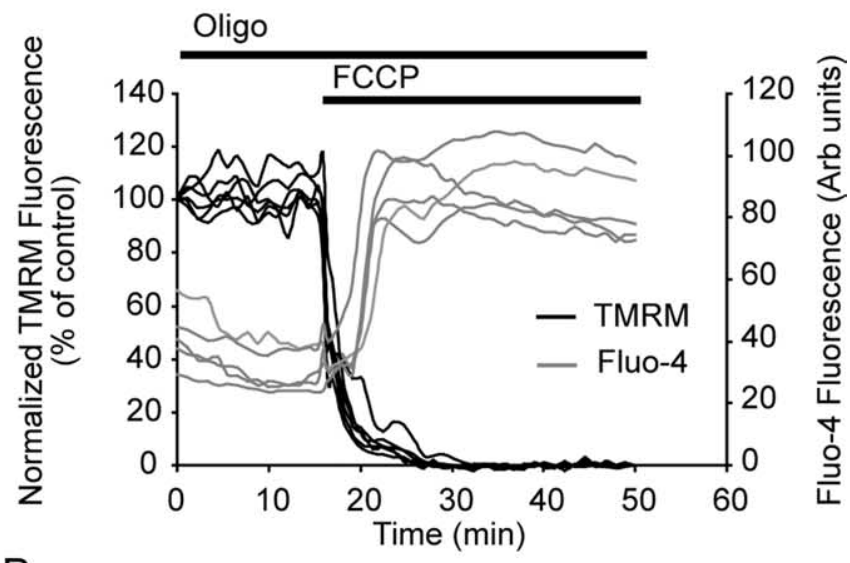

B
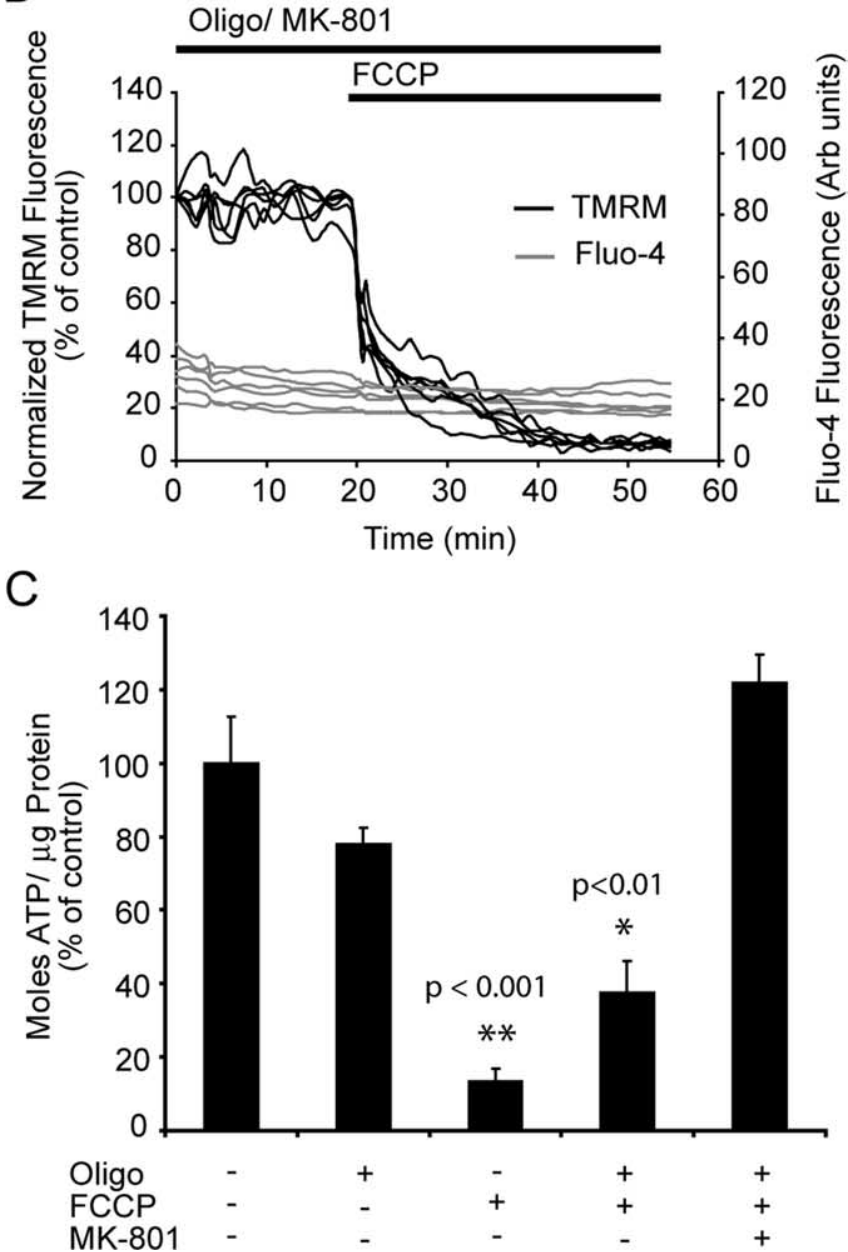

Figure 3. Protonophore addition induces a rapid collapse of $\mathrm{Ca}^{2+}$ homeostasis that is blocked with MK-801. A, $B$, Neurons were loaded with TMRM (30 nM) and Fluo-4 (3 $\mu \mathrm{M})$ for 30 min at $37^{\circ} \mathrm{C}$ and exposed to FCCP $(2 \mu \mathrm{M})$ in the presence of oligomycin $(2 \mu \mathrm{g} / \mathrm{ml})$ with $(A)$ or without $(\boldsymbol{B})$ MK-801 $(10 \mu \mathrm{M})$. A rapid increase in cytosolic $\mathrm{Ca}^{2+}$ accompanied the FCCP addition in neurons that did not have MK-801 present (experiments were repeated 3 times for each condition, with similar results). C, Neurons were treated with a combination of FCCP $(2 \mu \mathrm{M})$, oligomycin $(2 \mu \mathrm{g} / \mathrm{ml})$, and MK-801 (10 $\mu \mathrm{M})$ for $30 \mathrm{~min}$, and ATP levels were measured moles ATP $/ \mu \mathrm{g}$ protein. All data were normalized to control values for comparison between experiments (experiments were performed in triplicate in 3 separate cultures; ${ }^{* *} p<0.001 ;{ }^{*} p<0.01$ difference from control). Error bars indicate SEM. Oligo, Oligomycin; Arb units, arbitrary units. 
A

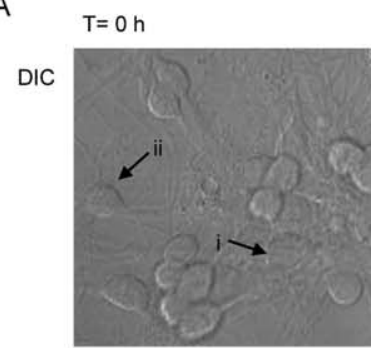

$T=30$ min Glutamate/Glycine

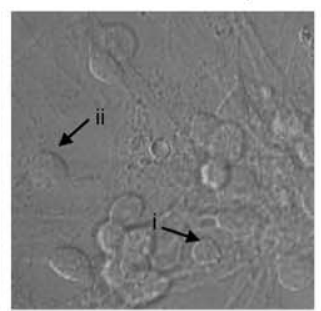

$\mathrm{T}=120 \mathrm{~min}$ Glutamate/Glycine

TMRM
$(30 \mathrm{nM})$
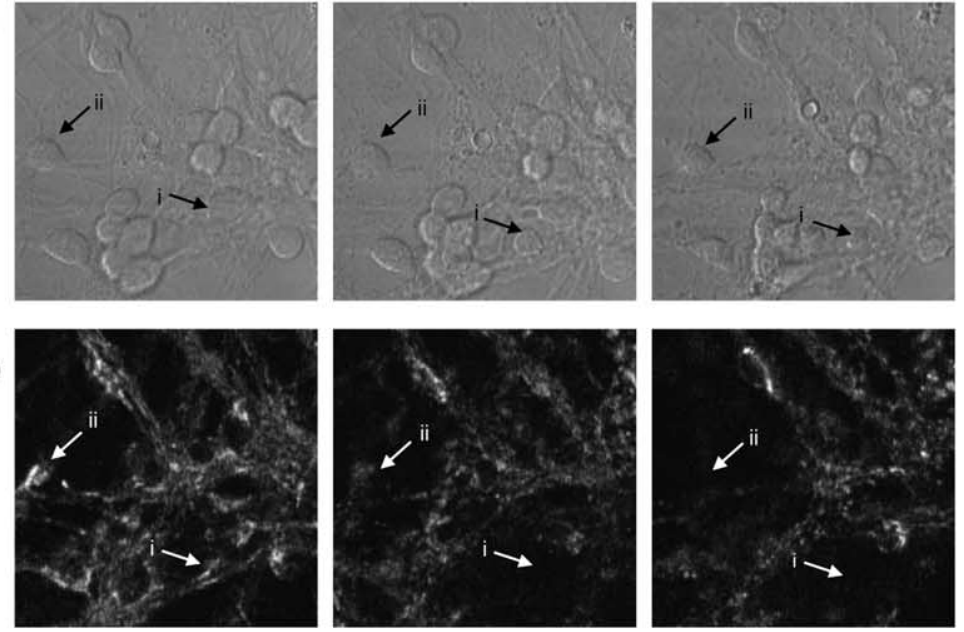

B

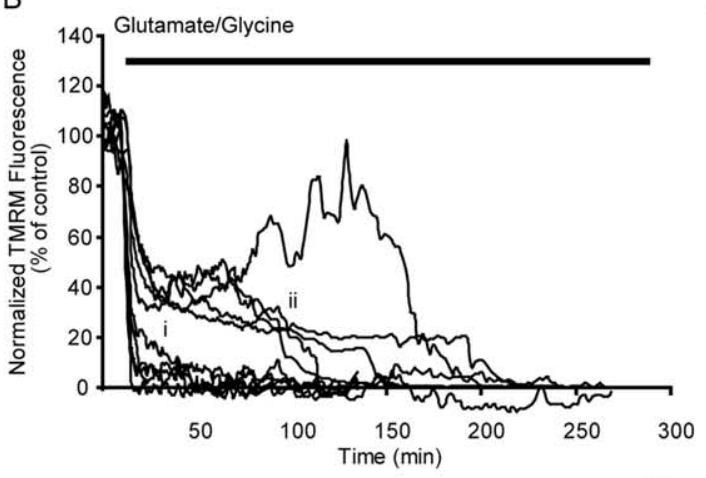

C.

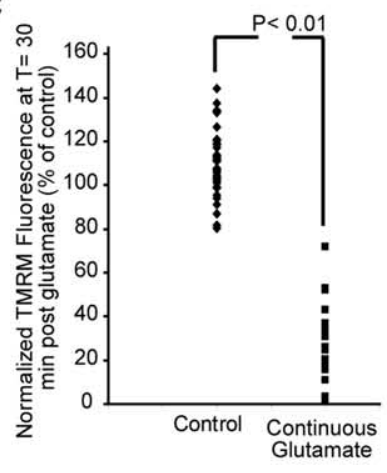

D

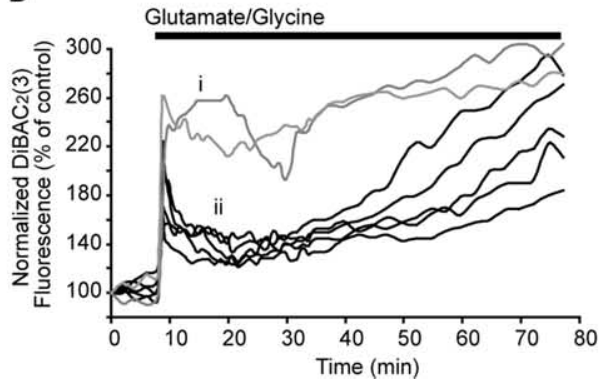

E

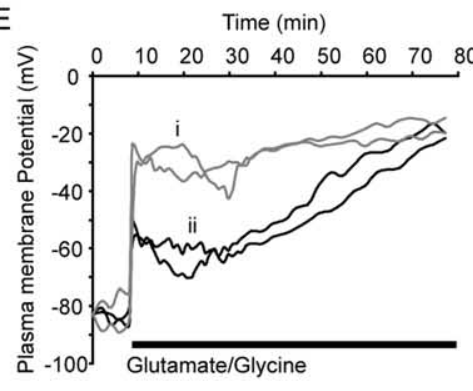

Figure 4. Prolonged glutamate excitation induces a rapid loss of $\Delta \Psi_{\mathrm{m}}$ and early necrotic injury in cerebellar granule neurons. Cerebellar granule neurons plated on Willco dishes were loaded with $30 \mathrm{~nm}$ TMRM and continuously exposed to glutamate/glycine $(100 \mu \mathrm{m} / 10 \mu \mathrm{M})$. TMRM fluorescence was then monitored over time, and images were taken at $1 \mathrm{~min}$ intervals. $A$, Differential interference contrast (DIC) and TMRM fluorescent images were chosen at selected time points $(0,30$, and 120 min during glutamate excitation) from a representative experiment. $\boldsymbol{B}$, Representative traces for whole-cell TMRM fluorescence in neurons during prolonged glutamate excitation. Two major subgroups were identified: traces that show a rapid collapse of $\Delta \Psi_{m}$ (i) and traces that show a partial recovery of $\Delta \Psi_{\mathrm{m}}$, followed by a secondary collapse of $\Delta \Psi_{\mathrm{m}}$ (ii). C, Whole-cell TMRM fluorescence in control neurons after $30 \mathrm{~min}$ and neurons treated with glutamate for $30 \mathrm{~min} . p<0.001$, difference between TMRM fluorescence for control neurons and neurons after 30 min continuous glutamate excitation (control, $n=39$; necrotic, $n=63$ ). D. Cerebellar granule neurons were loaded with the $\Delta \Psi_{\mathrm{p}}$-sensitive probe $\mathrm{DiBAC}_{2}(3)(1 \mu \mathrm{M})$ and continuously exposed to glutamate/glycine (100 $\mu \mathrm{m} / 10 \mu \mathrm{m}$ ). Neurons undergo a rapid monophasic (i) collapse of $\Delta \Psi_{\mathrm{p}}$ or a biphasic (ii) collapse of $\Delta \Psi_{\mathrm{p}}$ (traces are representative of those obtained from 3 separate experiments). $E$, Representative traces for modeled changes in $\Delta \Psi_{\mathrm{p}}(\boldsymbol{C})$ for neurons undergoing a rapid monophasic (i) collapse of $\Delta \Psi_{\mathrm{p}}$ or a biphasic (ii) collapse of $\Delta \Psi_{\mathrm{p}}$ when continuously exposed to glutamate/glycine $(100 \mu \mathrm{m} / 10 \mu \mathrm{m})$.

and the predictive changes in $\Delta \Psi_{\mathrm{p}}$ were calculated (Fig. $4 E$ ), the values for $\Delta \Psi_{\mathrm{p}}$ were found to be similar to those predicted form the modeled TMRM data (Fig. $5 B, D, F$ ). Therefore, it would appear that MATLAB-based computational models can accurately determine changes in both $\Delta \Psi_{\mathrm{m}}$ and $\Delta \Psi_{\mathrm{p}}$ from TMRM responses alone.

Hyperpolarization of $\Delta \Psi_{m}$ in apoptotic neurons after transient glutamate receptor excitation

Transient excitotoxicity results in a delayed neuronal injury that has mitochondrial dysfunction intricately linked with injury onset (Lankiewicz et al., 2000; Luetjens et al., 2000; Ward et al., 2000, 2006). Here, cerebellar granule neurons were stimulated for 5 min with glutamate/ glycine, allowed to recover, and monitored over a $24 \mathrm{~h}$ period (Ward et al., 2006). After transient glutamate excitation, only $2.9 \%$ of the neurons underwent rapid necrotic injury with an early loss of $\Delta \Psi_{\mathrm{m}}$ $(46.2 \pm 16.7 \mathrm{~min})$, neuronal swelling, and early membrane lysis. However, the majority of neurons monitored $(78.8 \%)$ displayed a delayed loss of $\Delta \Psi_{\mathrm{m}}(11.8 \pm 0.8 \mathrm{~h})$, cell shrinkage, and condensation of the nucleus within a $24 \mathrm{~h}$ period. An additional 18.2\% survived this injury and retained a hyperpolarized $\Delta \Psi_{\mathrm{m}}$ and normal cellular morphology for at least $24 \mathrm{~h}$ (Fig. $6 A, B$ ).

The MATLAB-based model was used (Fig. $1 A$ ) to interpret the changes in TMRM fluorescence for populations of individual neurons and provide output on changes in $\Delta \Psi_{\mathrm{m}}$ and $\Delta \Psi_{\mathrm{p}}$ during and after transient glutamate excitation. In the majority of neurons $(97.1 \%)$, a transient depolarization of $\Delta \Psi_{\mathrm{p}}$ was associated with glutamate receptor overactivation with values for $\Delta \Psi_{\mathrm{p}}$ returning to prestimulation levels within a relatively short (5-15 min) period of time (Fig. $7 B, D, F, H)$. Interestingly, the values for $\Delta \Psi_{\mathrm{m}}$ after glutamate excitation were found to be significantly higher $(p<0.001)$ than before glutamate excitation (Fig. $7 B, D, F, H$ ). Similar to the previous experiments, the output on the changes in $\Delta \Psi_{\mathrm{m}}$ and $\Delta \Psi_{\mathrm{p}}$ deducted from the computational analysis of the TMRM responses were validated with the $\Delta \Psi_{\mathrm{p}}$-sensitive probe $\operatorname{DiBAC}_{2}(3)$. An increase in $\operatorname{DiBAC}_{2}(3)$ fluorescence was associated with the initial glutamate excitation $\left(\Delta \Psi_{\mathrm{p}}\right.$ depolarization) (Fig. $6 D)$; after inhibition of glutamate receptor overactivation, the fluorescence recovered to prestimulation levels with no hyperpolarization of the $\Delta \Psi_{\mathrm{p}}$ (lower fluorescence than baseline) identified (Fig. 6D). Interestingly, when the $\mathrm{DiBAC}_{2}(3)$ responses were calculated using MATLAB software and the predictive changes in $\Delta \Psi_{\mathrm{p}}$ were calculated (Fig. $6 E$ ), the values for $\Delta \Psi_{\mathrm{p}}$ were again found to be similar to those predicted from the modeled TMRM data (Fig. $7 B, D, F, G)$. What is most significant from these results is the fact that the increase in TMRM fluorescence after glutamate excita- 
tion (Figs. 6, 7) is almost entirely attributable to a hyperpolarization of $\Delta \Psi_{\mathrm{m}}$ with little or no contribution from changes in $\Delta \Psi_{\mathrm{p}}($ Fig. $6 D, E)$.

Hyperpolarization of $\Delta \Psi_{m}$ is a predictor of survival time and tolerance to transient glutamate receptor excitation

Statistical analysis of the MATLAB-based computational model was performed to investigate whether changes in $\Delta \Psi_{\mathrm{m}}$ and $\Delta \Psi_{\mathrm{p}}$ after transient glutamate receptor overactivation could predict downstream injury or survival. Two major phases of change were determined during transient glutamate excitation: (1) the extent of the initial depolarization of $\Delta \Psi_{\mathrm{p}}$ during the glutamate excitation phase and (2) the hyperpolarization of $\Delta \Psi_{\mathrm{m}}$ after the excitation phase (Figs. 6, 7). When the single-cell data from a number of neuronal populations were characterized, correlations between the onset of injury (collapse of $\Delta \Psi_{\mathrm{m}}$ within the neuron) and changes in $\Delta \Psi_{\mathrm{m}}$ and $\Delta \Psi_{\mathrm{p}}$ could be established. A strong correlation was identified $\left(r^{2}=0.28 ; n=5\right.$ neuronal populations) between the extent of the initial depolarization and the onset of neuronal injury in individual population subsets (Fig. 7I), with a large depolarization of $\Delta \Psi_{\mathrm{p}}$ during the initial glutamate excitation phase associated with a more rapid onset of injury. The second and possibly more interesting correlation defined ( $r^{2}=0.23 ; n=5$ neuronal populations) is that between the extent of hyperpolarization after transient excitation within a population of cells and the onset of injury (Fig. 7J), with those neurons having a more pronounced hyperpolarization of $\Delta \Psi_{\mathrm{m}}$ during the recovery phase surviving longer. On further analysis of the TMRM fluorescence for those neurons that tolerated the glutamate insult, we identified that those neurons tolerant to transient glutamate excitation had a significantly $(p<0.001)$ higher TMRM fluorescence $(202.8 \pm 19.2 ; n=31)$ than neurons that underwent apoptosis (Fig. 6C). These data suggest that the extent of the hyperpolarization of $\Delta \Psi_{\mathrm{m}}$ (increase in TMRM fluorescence) after transient glutamate excitation is more closely associated with neuronal survival rather than injury.

\section{Enhanced glucose uptake and NADPH availability in} response to transient glutamate excitation

Because an increased $\Delta \Psi_{\mathrm{m}}$ is highly suggestive of alterations in neuronal metabolism, we investigated how glucose uptake, NADPH production, and neuronal ATP levels may be altered in relation to glutamate excitation. Prolonged glutamate excitation (dashed line) resulted in a significant $\left({ }^{\#} p<0.01\right)$ rapid and continuous decrease in both neuronal NADPH (Fig. $8 A, B$ ) and ATP (Fig. $8 C$ ) levels within the neurons. However, transient glutamate
B

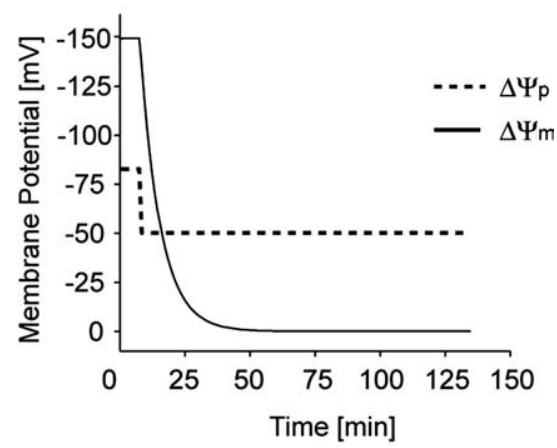

D

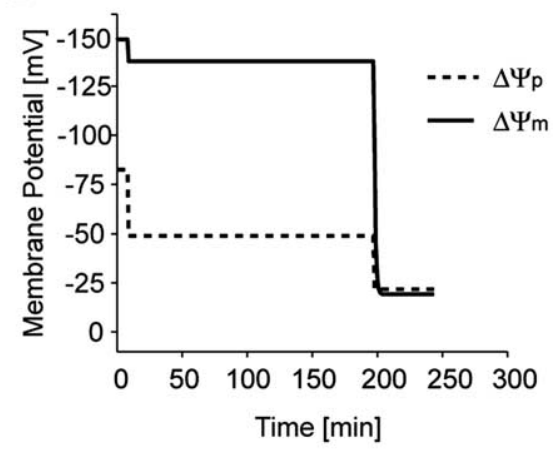

F

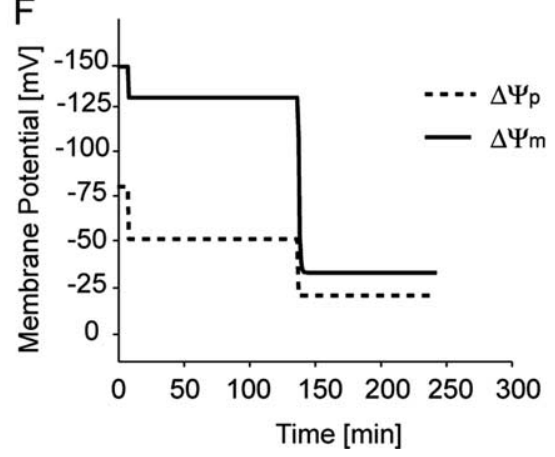

Figure 5. Computational modeling of TMRM traces for neurons during prolonged glutamate excitation. Cerebellar granule neurons plated on Willco dishes were loaded with $30 \mathrm{~nm}$ TMRM and continuously exposed to glutamate/glycine (100 $\mu \mathrm{m} / 10 \mu \mathrm{m})$. TMRM fluorescence was then monitored over time, and images were taken at 2 min intervals. $\boldsymbol{A}$, Representative TMRM fluorescent necresis. $\boldsymbol{C}, \boldsymbol{E}$, Representative TMRM fluorescent traces and fitted traces for neurons that have a biphasic response during glutamate-induced necrosis. $B, D, F$, Modeled changes in both $\Delta \Psi_{\mathrm{p}}$ (dashed lines) and $\Delta \Psi_{\mathrm{m}}$ (solid line) for the fitted traces in figures $\boldsymbol{A}, \boldsymbol{C}$, and $\boldsymbol{E}$, respectively. TMRM $(\boldsymbol{A}, \boldsymbol{C}, \boldsymbol{E})$ traces are representative of traces obtained from eight separate experiments from different cultures. a.u., Arbitrary units.

excitation (solid line) resulted in a transient decrease in both neuronal NADPH and ATP levels that was followed by a significant $\left({ }^{\star} p<0.01\right)$ and sustained increase in both (Fig. $8 A, B$ ) NADPH and ATP. This increase in NAHPD and ATP levels was also coupled to a significant increase in glucose uptake (Fig. $8 D$ ) as measured with ${ }^{3} \mathrm{H}$-2-deoxyglucose. These alterations in neuronal metabolism, in particular the NADPH levels that could be determined in real time, closely paralleled the hyperpolarization of $\Delta \Psi_{\mathrm{m}}$ identified after transient glutamate excitation (Figs. 6B, 7).

\section{Discussion}

Computational modeling of $\Delta \Psi_{\mathrm{m}}$ and $\Delta \Psi_{\mathrm{p}}$ from TMRM fluorescent traces

Cationic fluorescent probes (TMRM, TMRE, rhodamine-123, JC-1) are an invaluable tool for monitoring mitochondrial func- 
A

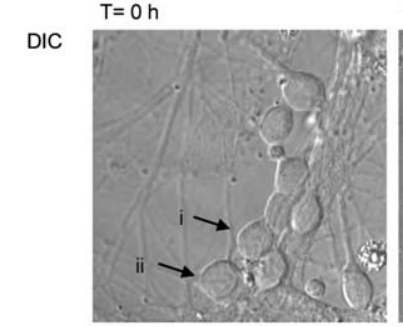

$\mathrm{T}=2 \mathrm{~h}$
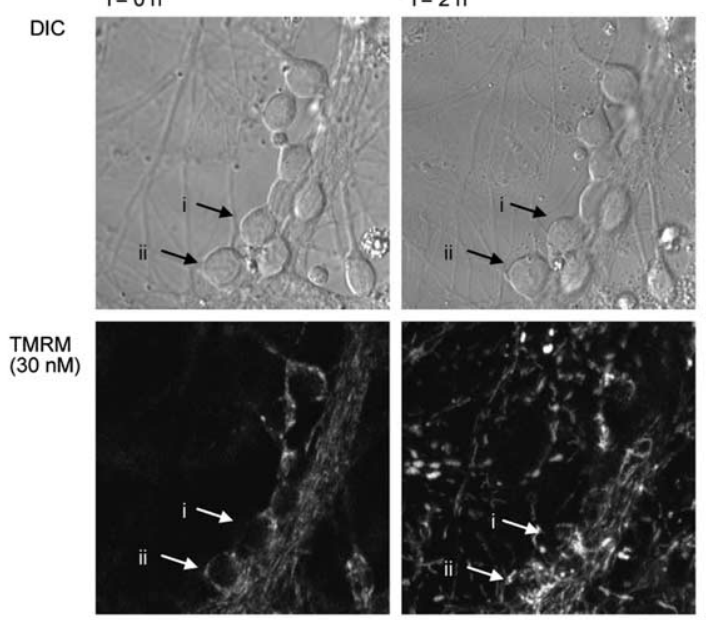

$\mathrm{T}=14 \mathrm{~h}$
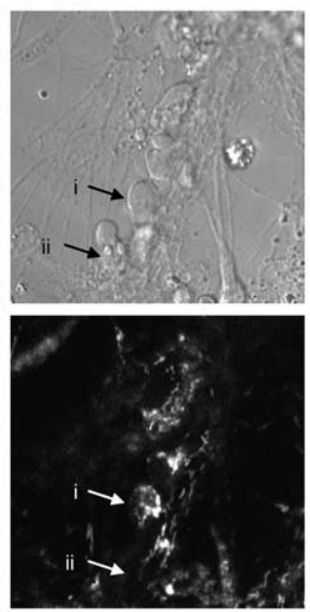

B

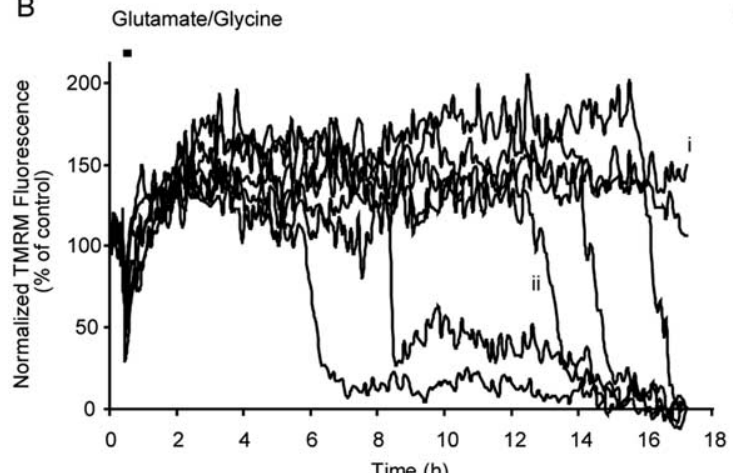

D

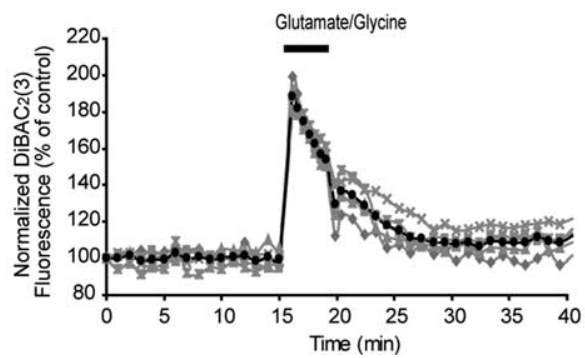

E

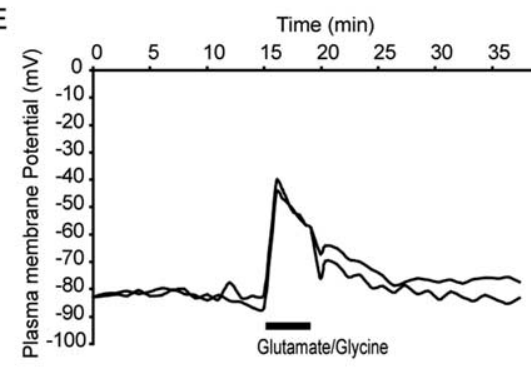

Figure 6. Transient glutamate excitation results in a hyperpolarization $\Delta \Psi_{\mathrm{m}}$ and a late apoptotic injury in cerebellar granule neurons. Cerebellar granule neurons plated on Willco dishes were loaded with $30 \mathrm{~nm}$ TMRM and exposed to glutamate/glycine $(100 \mu \mathrm{m} / 10 \mu \mathrm{M})$ for $5 \mathrm{~min}$. TMRM fluorescence was then monitored over time, and images were taken at 5 min intervals. $\boldsymbol{A}$, Differential interference contrast (DIC) and TMRM fluorescent images were chosen at selected time points ( $0 \mathrm{~min}, 2 \mathrm{~h}$, and $14 \mathrm{~h}$ after glutamate) from a representative experiment. $\boldsymbol{B}$, Representative traces for whole-cell TMRM fluorescence in neurons during prolonged glutamate excitation. Two major subgroups are shown: traces that show a secondary collapse of $\Delta \Psi_{\mathrm{m}}$ downstream of excitation (i) and traces that show a collapse of $\Delta \Psi_{\mathrm{m}}$ within $24 \mathrm{~h}$ (ii). C, Whole-cell TMRM fluorescence in control neurons after 120 min and neurons 120 min after glutamate excitation. $p<0.01$, difference between TMRM fluorescence for control neurons and apoptotic neurons 120 min after transient glutamate excitation; $p<0.001$ difference between TMRM fluorescence for apoptotic neurons $120 \mathrm{~min}$ after transient excitation compared with neurons that survive for $>24 \mathrm{~h}$ after glutamate excitation (control, $n=39$; apoptotic, $n=134$; live, $n=31$ ). D, Cerebellar granule neurons were loaded with the $\Delta \Psi_{\mathrm{p}}$-sensitive probe $\mathrm{DiBAC}_{2}(3)(1 \mu \mathrm{m})$ and transiently $(5 \mathrm{~min})$ exposed to glutamate/glycine (100 $\left.\mu \mathrm{m} / 10 \mu \mathrm{m}\right)$. Fluorescence recovers close to preexposure levels (average response dark trace) after the addition of glutamate (traces are representative of those obtained from 3 separate experiments). $\boldsymbol{E}$, Representative traces for modeled changes in $\Delta \Psi_{\mathrm{p}}$ for neurons transiently exposed to glutamate. icance of changes in $\Delta \Psi_{\mathrm{p}}$ on the total cellular fluorescence (Nicholls and Ward, 2000; Ward et al., 2000). Here, we have successfully created an automated MATLAB-based computational model that uses the sensitivity of TMRM fluorescence to changes in both $\Delta \Psi_{\mathrm{m}}$ and $\Delta \Psi_{\mathrm{p}}$ providing predictive output on changes in $\Delta \Psi_{\mathrm{m}}$ and $\Delta \Psi_{\mathrm{p}}$, removing the need for additional plasma membrane indicators or manual parameter fitting. Using the plasma-sensitive probe $\operatorname{DiBAC}_{2}(3)$ (Ehrenberg et al., 1988; Gonzalez and Maher, 2002), we have validated the sensitivity and accuracy of the computational model created in predicting changes in $\Delta \Psi_{\mathrm{p}}$. With this technology, we have been able to evaluate changes that occur at a $\Delta \Psi_{\mathrm{m}}$ and $\Delta \Psi_{\mathrm{p}}$ level in models of glutamate-induced necrosis, apoptosis, and tolerance, providing us with novel insights into the bioenergetic/metabolic mechanisms associated with glutamate regulation and glutamate-induced injury and tolerance.

\section{Effects of "mitochondrial" toxins on} $\Delta \Psi_{p}, \mathrm{Ca}^{2+}$ uptake, and glutamate release

In control experiments (Fig. 3), a combination of the ATP synthase inhibitor oligomycin and the protonophore FCCP were used to collapse $\Delta \Psi_{\mathrm{m}}$ in neurons, a technique routinely used to nullify mitochondrial function within neurons (Stout et al., 1998; Ward et al., 2005). The addition of oligomycin alone resulted in only minor changes in $\Delta \Psi_{\mathrm{m}}$ and neuronal ATP levels; however, the addition of FCCP resulted in the expected collapse of $\Delta \Psi_{\mathrm{m}}$ that was coupled with an unexpected decrease in $\Delta \Psi_{\mathrm{p}}$, loss of $\mathrm{Ca}^{2+}$ homeostasis, and a significant decrease in neuronal ATP levels. Because the addition of the NMDA receptor antagonist MK-801 blocked these events, it implies that a depolarization of synaptic mitochondria was sufficient to induce glutamate release. Presynaptic mitochondria have a functional role in the regulation of $\mathrm{Ca}^{2+}$ (Yang et al., 2003; Brown et al., 2006; Ly and Verstreken, 2006; Mironov and Symonchuk, 2006) within synaptic vesicles; indeed, recent studies have shown that the endoplasmic reticulum (ER) and mitochondria bidirectionally exchange $\mathrm{Ca}^{2+}$ within the synapse tion in intact cells during excitotoxic injury (Khodorov et al., 1996; White and Reynolds, 1996; Kiedrowski, 1998; Prehn, 1998; Stout et al., 1998; Ward et al., 2000; Buckman et al., 2001). However, because of the complex nature of these probes and their sensitivity to changes in both $\Delta \Psi_{\mathrm{m}}$ and $\Delta \Psi_{\mathrm{p}}$, the fluorescence responses obtained have often been misinterpreted because of an overestimation of changes in $\Delta \Psi_{\mathrm{m}}$ by underestimating the signifand that $\mathrm{Ca}^{2+}$ released from the ER or mitochondria is sufficient to evoke exocytosis (Mironov and Symonchuk, 2006). If synaptic mitochondria are highly involved in the regulation of synaptic $\mathrm{Ca}^{2+}$ (Mironov and Symonchuk, 2006), a mitochondrial depolarization and reversal of the $\mathrm{Ca}^{2+}$ uniporter would provide sufficient $\mathrm{Ca}^{2+}$ to enable glutamate exocytosis to occur. Yang et al. (2003) also identified that $\mathrm{Ca}^{2+}$ released from mitochondria 
through the mitochondrial $\mathrm{Na}^{+}-\mathrm{Ca}^{2+}$ exchanger is sufficient to induce synaptic glutamate release. Additionally, Budd and Nicholls (1996a) previously characterized a protonophore releasable pool of $\mathrm{Ca}^{2+}$ within neurons. Therefore, it appears that the manipulation of $\Delta \Psi_{\mathrm{m}}$ with mitochondrial toxins may alter $\mathrm{Ca}^{2+}$ sequestration within synaptic mitochondria and thereby alter glutamate regulation within the synapse.

\section{Glutamate-induced necrosis}

The injury identified during prolonged glutamate excitation in this study is very much in agreement with previous studies including work performed by ourselves (Ankarcrona et al., 1995; White and Reynolds, 1996; Prehn, 1998; Stout et al., 1998; Ward et al., 2000), with prolonged glutamate excitation resulting in a monophasic or biphasic collapse of $\Delta \Psi_{\mathrm{m}}$, paralleled with a decrease in $\Delta \Psi_{\mathrm{p}}$, rapid neuronal swelling, and early membrane lysis. Prolonged glutamate excitation also resulted in the rapid decay of ATP as a consequence of the increased activity of both the $\mathrm{Na}^{+} / \mathrm{K}^{+}$and $\mathrm{Ca}^{2+}$ ATPases at the plasma membrane.

What is intriguing from the data presented here is the biphasic $\operatorname{DiBAC}_{2}(3)$ responses (Fig. $4 E$ ) during glutamate excitation, where the loss of $\Delta \Psi_{\mathrm{p}}$ is not a single event but appears to be a slowly developing process. So what may induce a slow loss of $\Delta \Psi_{\mathrm{p}}$ ? The preservation of a polarized plasma membrane is dependent on the regulation of ionic homeostasis by $\mathrm{Na}^{+} / \mathrm{K}^{+}$and $\mathrm{Ca}^{2+}$ ATPases, as well as the $\mathrm{Na}^{+} / \mathrm{Ca}^{2+}$ exchanger. During glutamate excitation, a high concentration of $\mathrm{Ca}^{2+}$ is retained within the cytosol and mitochondrial matrix (Tymianski et al., 1993a; Budd and Nicholls, 1996b; Stout et al., 1998; Brocard et al., 2001; Ward et al., 2005). This prolonged increase in cytosolic and mitochondrial $\mathrm{Ca}^{2+}$ has been shown to increase calpain activity (Siman et al., 1989; Faddis et al., 1997; Lankiewicz et al., 2000), and it has been suggested that this increased calpain activation leads to cleavage of the $\mathrm{Na}^{+} / \mathrm{Ca}^{2+}$ exchanger, resulting in the progressive disruption of cellular homeostasis (Bano et al., 2005). Additionally, the activation of TRP (transient receptor potential) channels, post glutamate excitation, may also play an integral part in the development of this secondary, slow $\Delta \Psi_{\mathrm{p}}$ depolarization (Aarts et al., 2003).
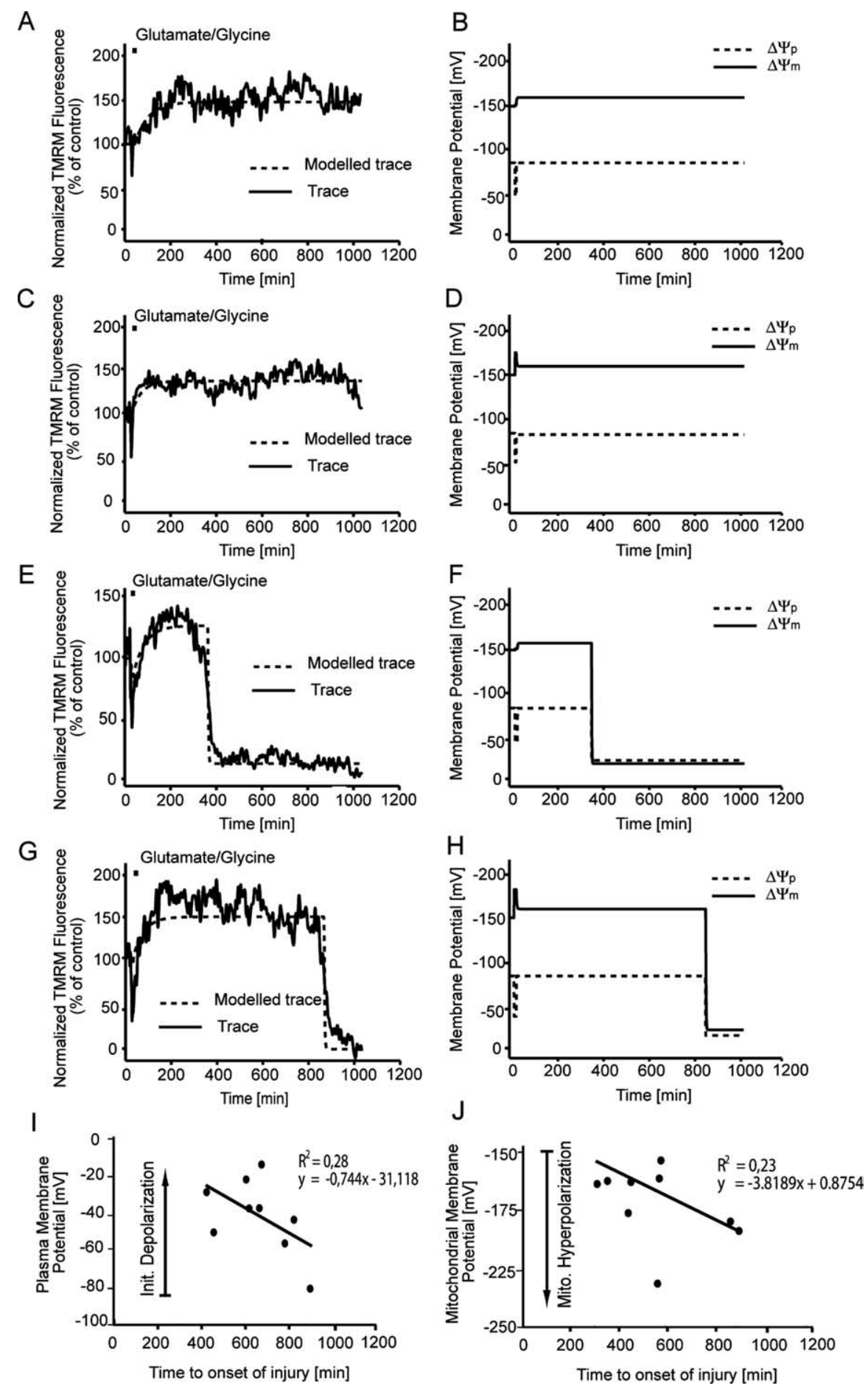

Figure 7. Computational modeling of TMRM traces for cerebellar granule neurons after transient glutamate excitation. Cerebellar granule neurons plated on Willco dishes were loaded with $30 \mathrm{~nm}$ TMRM and exposed to glutamate/glycine $(100 \mu \mathrm{m} / 10 \mu \mathrm{m})$ for 5 min. TMRM fluorescence was then monitored over time, and images were taken at 5 min intervals. $A, C$, Representative TMRM fluorescent traces (solid line) and fitted traces (dashed lines) for neurons that undergo apoptosis after transient glutamate excitation. $\boldsymbol{E}, \boldsymbol{G}$, Representative TMRM fluorescent traces and fitted traces for neurons that do not undergo apoptosis after transient glutamate excitation. $\boldsymbol{B}, \boldsymbol{D}, \boldsymbol{F}, \boldsymbol{H}$, Modeled changes in both $\Delta \Psi_{\mathrm{p}}$ (dashed lines) and $\Delta \Psi_{\mathrm{m}}$ (solid line) for the fitted traces in $A, C, E$, and $F$, respectively. TMRM traces $(A, C, E, G)$ are representative of traces obtained from eight separate experiments from different cultures. $I$, The fitted initial depolarization of $\Delta \Psi_{\mathrm{p}}$ during glutamate excitation is plotted against the onset of injury (collapse of TMRM signal; $n=5$ populations of neurons). $J$, The fitted maximum mitochondrial hyperpolarization of $\Delta \Psi_{\mathrm{m}}$ against onset of injury after glutamate excitation ( $n=5$ populations of neurons). 
A
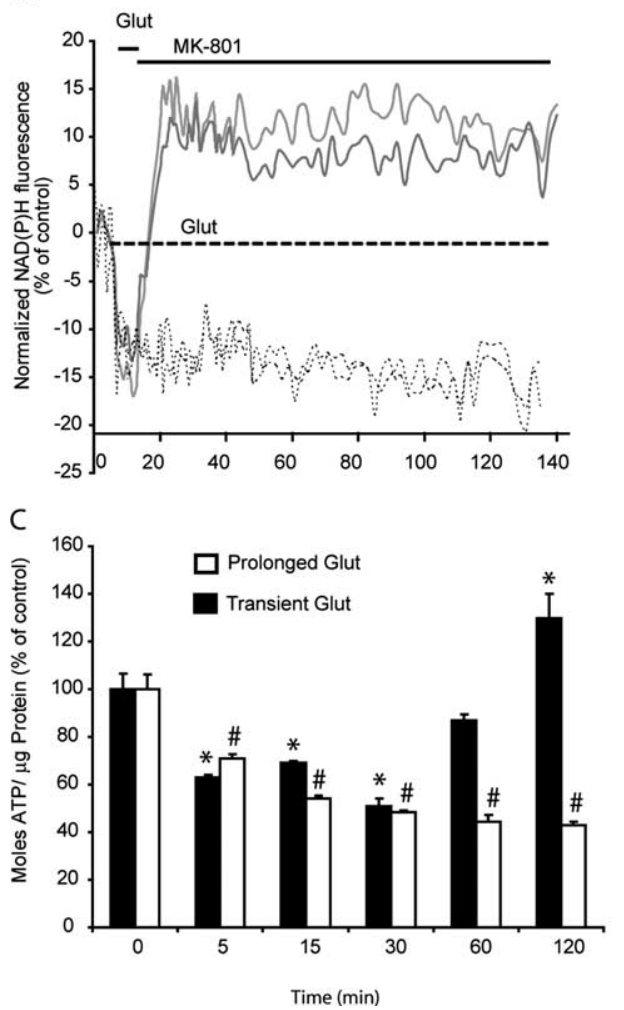

Figure 8. Glutamate (Glut) induced changes in neuronal NADPH, ATP, and glucose uptake. Cerebellar granule neurons plated on Willco dishes were exposed to glutamate/glycine (100 $\mu \mathrm{m} / 10 \mu \mathrm{M}$ ) continuously (dashed line) or for $5 \mathrm{~min}$ (solid line) before termination of NMDA receptor activation with MK-801 $(10 \mu \mathrm{M}) . \boldsymbol{A}, \boldsymbol{B}, \mathrm{NADPH}$ autofluorescence was monitored over time $(\boldsymbol{A})$ and at selected time points $(0,10$ and $60 \mathrm{~min} ; \boldsymbol{B})$ chosen before, during, and after glutamate excitation for statistical analysis. (At least 5 cells were analyzed per experiment, and the experiment was repeated in three different cultures. ${ }^{\#} p<0.01$; ${ }^{*} p<0.01$, difference from respective control.) $C$, Cerebellar granule neurons plated in 24-well plates were exposed to glutamate/glycine $(100 \mu \mathrm{m} / 10 \mu \mathrm{m})$ for $5 \mathrm{~min}$ or continuously, and their ATP content was measured (moles ATP/ $\mu \mathrm{g}$ protein) at the times indicated. Data are represented as percentage of control response $\left(n=3\right.$ experiments in triplicate; ${ }^{\#} p<0.01 ;{ }^{*} p<0.01$, difference from respective control). $\boldsymbol{D}$, (erebellar granule neurons plated in 96 -well plates were exposed to glutamate/glycine $(100 \mu \mathrm{m} / 10 \mu \mathrm{m})$ for $10 \mathrm{~min}$ and washed, and the medium was replaced with buffer containing ${ }^{3} \mathrm{H}$-2-deoxyglucose for $20 \mathrm{~min}$. The cells were washed twice, and the ${ }^{3} \mathrm{H}$-2-deoxyglucose was measured in a Matrix-96 beta counter for 20 min. Data are presented as counts per minute (CPM) for control (washed neurons) and glutamate-treated neurons ( 6 wells were examined per condition per experiment and repeated in 3 separate cultures; $\left.{ }^{*} p<0.01\right)$. Error bars indicate SEM.

\section{Glutamate-induced apoptosis and tolerance}

In contrast to the necrotic injury induced by prolonged glutamate excitation, transient glutamate excitation resulted in a reversible depolarization of $\Delta \Psi_{\mathrm{p}}$ that was followed by a prolonged hyperpolarization of $\Delta \Psi_{\mathrm{m}}$, with the subsequent collapse of both $\Delta \Psi_{\mathrm{m}}$ and $\Delta \Psi_{\mathrm{p}}$, cell shrinkage and nuclear condensation occurring hours downstream of the initial excitation (Lankiewicz et al., 2000; Luetjens et al., 2000; Ward et al., 2000). Using the MATLAB-based computational model, we were able to detect changes in both $\Delta \Psi_{\mathrm{m}}$ and $\Delta \Psi_{\mathrm{p}}$ relative to injury onset for populations of single cells after transient glutamate excitation. A correlation was identified between the extent of the initial depolarization of $\Delta \Psi_{\mathrm{p}}$ during the glutamate excitation phase and the onset of injury within neurons, with those neurons having a more pronounced depolarization of $\Delta \Psi_{p}$ during the excitation phase entering a more rapid cell death. Previous studies have identified that excitotoxic injury is highly dependent on the duration and intensity of glutamate/NMDA receptor overactivation (Choi, 1987; Tymianski et al., 1993b; Sattler et al., 1998). Because of the variability in the initial $\Delta \Psi_{\mathrm{p}}$ depolarization identified after glutamate excitation in this study, it is evident that there are marked variations in the type and number of glutamate/NMDA receptors present at the plasma membrane between neurons within a "homogenous" culture.

The most significant findings in this study involve the relationship between the hyperpolarization of $\Delta \Psi_{\mathrm{m}}$, the changes in neuronal metabolism, and neuronal survival after transient glutamate excitation. A hyperpolarization of $\Delta \Psi_{\mathrm{m}}$ has previously been described in hippocampal neurons exposed to staurosporine (Poppe et al., 2001) and $30 \mathrm{~min}$ oxygen glucose deprivation (Iijima et al., 2003), and also in primary rodent cortical neurons (Perry et al., 2005) after the induction of the regulatory protein Tat (transactivator of transcription) by HIV-1. The increase in $\Delta \Psi_{\mathrm{m}}$ identified was associated with the onset of apoptotic injury, as is true for the majority of neurons in this study. Here, we could rapidly interpret the TMRM fluorescent responses for a number of populations of single-cell data with the MATLAB-based computational model. From this, a positive correlation was established between $\Delta \Psi_{\mathrm{m}}$ and neuronal survival, with neurons displaying a more pronounced hyperpolarization of $\Delta \Psi_{\mathrm{m}}$ surviving longer, a correlation that may have been inadvertently missed in previous studies (Poppe et al., 2001; Iijima et al., 2003; Perry et al., 2005). Additionally, the MATLAB-based analysis allowed us to identify a subset of neurons tolerant to glutamate excitation that had a significantly higher hyperpolarization of $\Delta \Psi_{\mathrm{m}}$ than apoptotic neurons after transient glutamate excitation.

Why does a hyperpolarization of $\Delta \Psi_{\mathrm{m}}$ promote or indicate survival? Glutamate excitation results in an early and rapid depletion in neuronal ATP levels (Atlante et al., 1996; Almeida et al., 1998). To counteract this loss of ATP, neurons can increase their capacity to provide extra fuel, $\mathrm{NADPH} / \mathrm{FADH}_{2}$, to meet the energy demands within the cell (Shuttleworth et al., 2003; Brennan et al., 2006). Because glutamate excitation results in the accumulation of $\mathrm{Ca}^{2+}$ within the mitochondrial matrix (Budd and Nicholls, 1996b; Wang and Thayer, 1996), the activation state of mitochondrial dehydrogenases will be altered increasing proton extrusion (Hansford, 1994a,b). We have previously identified that mitochondria retain $\mathrm{Ca}^{2+}$ within the mitochondrial matrix after transient glutamate excitation (Ward et al., 2005), which may lead to a prolonged alteration in dehydrogenase activity. What is evident in this study is that after glutamate excitation, the energetic state within neurons undergoing apoptosis or that are tolerant to the stimulus does not return to the prestimulus resting state, with a sustained increased $\Delta \Psi_{\mathrm{m}}$ that is coupled with increased glucose uptake and NADPH availability within the neurons.

Our key finding that neurons with an increased $\Delta \Psi_{\mathrm{m}}$ (and capacity to increase mitochondrial substrates NADPH and $\mathrm{FADH}_{2}$ ) after glutamate excitation survive longer or tolerate the stimulus is also supported by Vergun et al. (2003), who have 
shown that an inhibition of glycolysis is sufficient to induce a hypersensitivity of primary cortical neurons to glutamate excitation. It would therefore appear that the injury or tolerance induced is a function of the availability of ATP within the cell, with any variability between responses dictated by the ability of each neuron to produce ATP, a finding that may have a significant impact for our understanding of neuronal conditioning and tolerance.

\section{References}

Aarts M, Iihara K, Wei WL, Xiong ZG, Arundine M, Cerwinski W, MacDonald JF, Tymianski M (2003) A key role for TRPM7 channels in anoxic neuronal death. Cell 115:863-877.

Almeida A, Heales SJ, Bolanos JP, Medina JM (1998) Glutamate neurotoxicity is associated with nitric oxide-mediated mitochondrial dysfunction and glutathione depletion. Brain Res 790:209-216.

Ankarcrona M, Dypbukt JM, Bonfoco E, Zhivotovsky B, Orrenius S, Lipton SA, Nicotera P (1995) Glutamate-induced neuronal death: a succession of necrosis or apoptosis depending on mitochondrial function. Neuron 15:961-973.

Atlante A, Gagliardi S, Minervini GM, Marra E, Passarella S, Calissano P (1996) Rapid uncoupling of oxidative phosphorylation accompanies glutamate toxicity in rat cerebellar granule cells. NeuroReport 7:2519-2523.

Bano D, Young KW, Guerin CJ, Lefeuvre R, Rothwell NJ, Naldini L, Rizzuto R, Carafoli E, Nicotera P (2005) Cleavage of the plasma membrane $\mathrm{Na}+/ \mathrm{Ca} 2+$ exchanger in excitotoxicity. Cell 120:275-285.

Brennan AM, Connor JA, Shuttleworth CW (2006) NAD(P)H fluorescence transients after synaptic activity in brain slices: predominant role of mitochondrial function. J Cereb Blood Flow Metab 26:1389-1406.

Brocard JB, Tassetto M, Reynolds IJ (2001) Quantitative evaluation of mitochondrial calcium content in rat cortical neurones following a glutamate stimulus. J Physiol (Lond) 531:793-805.

Brown MR, Sullivan PG, Geddes JW (2006) Synaptic mitochondria are more susceptible to $\mathrm{Ca} 2+$ overload than nonsynaptic mitochondria. J Biol Chem 281:11658-11668.

Buckman JF, Hernandez H, Kress GJ, Votyakova TV, Pal S, Reynolds IJ (2001) MitoTracker labeling in primary neuronal and astrocytic cultures: influence of mitochondrial membrane potential and oxidants. J Neurosci Methods 104:165-176.

Budd SL, Nicholls DG (1996a) A reevaluation of the role of mitochondria in neuronal Ca2 + homeostasis. J Neurochem 66:403-411.

Budd SL, Nicholls DG (1996b) Mitochondria, calcium regulation, and acute glutamate excitotoxicity in cultured cerebellar granule cells. J Neurochem 67:2282-2291.

Budd SL, Tenneti L, Lishnak T, Lipton SA (2000) Mitochondrial and extramitochondrial apoptotic signaling pathways in cerebrocortical neurons. Proc Natl Acad Sci USA 97:6161-6166.

Castilho RF, Hansson O, Ward MW, Budd SL, Nicholls DG (1998) Mitochondrial control of acute glutamate excitotoxicity in cultured cerebellar granule cells. J Neurosci 18:10277-10286.

Castilho RF, Ward MW, Nicholls DG (1999) Oxidative stress, mitochondrial function, and acute glutamate excitotoxicity in cultured cerebellar granule cells. J Neurochem 72:1394-1401.

Choi DW (1987) Ionic dependence of glutamate neurotoxicity. J Neurosci 7:369-379.

Choi DW (1994) Glutamate receptors and the induction of excitotoxic neuronal death. Prog Brain Res 100:47-51.

Dussmann H, Rehm M, Kogel D, Prehn JH (2003) Outer mitochondrial membrane permeabilization during apoptosis triggers caspaseindependent mitochondrial and caspase-dependent plasma membrane potential depolarization: a single-cell analysis. J Cell Sci 116:525-536.

Ehrenberg B, Montana V, Wei MD, Wuskell JP, Loew LM (1988) Membrane potential can be determined in individual cells from the nernstian distribution of cationic dyes. Biophys J 53:785-794.

Faddis BT, Hasbani MJ, Goldberg MP (1997) Calpain activation contributes to dendritic remodeling after brief excitotoxic injury in vitro. J Neurosci 17:951-959.

Freedman JC, Novak TS (1989) Optical measurement of membrane potential in cells, organelles, and vesicles. Methods Enzymol 172:102-122.

Gerencser AA, Adam-Vizi V (2005) Mitochondrial Ca2+ dynamics reveals limited intramitochondrial Ca2+ diffusion. Biophys J 88:698-714.
Gonzalez JE, Maher MP (2002) Cellular fluorescent indicators and voltage/ ion probe reader (VIPR) tools for ion channel and receptor drug discovery. Receptors Channels 8:283-295.

Hansford RG (1994a) Physiological role of mitochondrial Ca2 + transport. J Bioenerg Biomembr 26:495-508.

Hansford RG (1994b) Role of calcium in respiratory control. Med Sci Sports Exerc 26:44-51.

Iijima T, Mishima T, Akagawa K, Iwao Y (2003) Mitochondrial hyperpolarization after transient oxygen-glucose deprivation and subsequent apoptosis in cultured rat hippocampal neurons. Brain Res 993:140-145.

Keelan J, Vergun O, Duchen MR (1999) Excitotoxic mitochondrial depolarisation requires both calcium and nitric oxide in rat hippocampal neurons. J Physiol (Lond) 520:797-813.

Khodorov B, Pinelis V, Vergun O, Storozhevykh T, Vinskaya N (1996) Mitochondrial deenergization underlies neuronal calcium overload following a prolonged glutamate challenge. FEBS Lett 397:230-234.

Kiedrowski L (1998) The difference between mechanisms of kainate and glutamate excitotoxicity in vitro: osmotic lesion versus mitochondrial depolarization. Restor Neurol Neurosci 12:71-79.

Kushnareva YE, Wiley SE, Ward MW, Andreyev AY, Murphy AN (2005) Excitotoxic injury to mitochondria isolated from cultured neurons. J Biol Chem 280:28894-28902.

Lankiewicz S, Marc Luetjens C, Truc Bui N, Krohn AJ, Poppe M, Cole GM, Saido TC, Prehn JH (2000) Activation of calpain I converts excitotoxic neuron death into a caspase-independent cell death. J Biol Chem 275:17064-17071.

Luetjens CM, Bui NT, Sengpiel B, Munstermann G, Poppe M, Krohn AJ, Bauerbach E, Krieglstein J, Prehn JH (2000) Delayed mitochondrial dysfunction in excitotoxic neuron death: cytochrome $\mathrm{c}$ release and a secondary increase in superoxide production. J Neurosci 20:5715-5723.

Ly CV, Verstreken P (2006) Mitochondria at the synapse. Neuroscientist 12:291-299.

Mironov SL, Symonchuk N (2006) ER vesicles and mitochondria move and communicate at synapses. J Cell Sci 119:4926-4934.

Nicholls DG (2002) Mitochondrial function and dysfunction in the cell: its relevance to aging and aging-related disease. Int J Biochem Cell Biol 34:1372-1381.

Nicholls DG (2006) Simultaneous monitoring of ionophore- and inhibitormediated plasma and mitochondrial membrane potential changes in cultured neurons. J Biol Chem 281:14864-14874.

Nicholls DG, Budd SL (2000) Mitochondria and neuronal survival. Physiol Rev 80:315-360.

Nicholls DG, Ferguson SJ (1992) Bioenergetics 2. London: Academic.

Nicholls DG, Ward MW (2000) Mitochondrial membrane potential and neuronal glutamate excitotoxicity: mortality and millivolts. Trends Neurosci 23:166-174.

Perry SW, Norman JP, Litzburg A, Zhang D, Dewhurst S, Gelbard HA (2005) HIV-1 transactivator of transcription protein induces mitochondrial hyperpolarization and synaptic stress leading to apoptosis. J Immunol 174:4333-4344.

Poppe M, Reimertz C, Dussmann H, Krohn AJ, Luetjens CM, Bockelmann D, Nieminen AL, Kogel D, Prehn JH (2001) Dissipation of potassium and proton gradients inhibits mitochondrial hyperpolarization and cytochrome $c$ release during neural apoptosis. J Neurosci 21:4551-4563.

Prehn JH (1998) Mitochondrial transmembrane potential and free radical production in excitotoxic neurodegeneration. Naunyn Schmiedebergs Arch Pharmacol 357:316-322.

Sattler R, Charlton MP, Hafner M, Tymianski M (1998) Distinct influx pathways, not calcium load, determine neuronal vulnerability to calcium neurotoxicity. J Neurochem 71:2349-2364.

Shuttleworth CW, Brennan AM, Connor JA (2003) NAD(P)H fluorescence imaging of postsynaptic neuronal activation in murine hippocampal slices. J Neurosci 23:3196-3208.

Siman R, Noszek JC, Kegerise C (1989) Calpain I activation is specifically related to excitatory amino acid induction of hippocampal damage. J Neurosci 9:1579-1590.

Stout AK, Raphael HM, Kanterewicz BI, Klann E, Reynolds IJ (1998) Glutamate-induced neuron death requires mitochondrial calcium uptake. Nat Neurosci 1:366-373.

Tymianski M, Charlton MP, Carlen PL, Tator CH (1993a) Secondary Ca2+ overload indicates early neuronal injury which precedes staining with viability indicators. Brain Res 607:319-323. 
Tymianski M, Charlton MP, Carlen PL, Tator CH (1993b) Source specificity of early calcium neurotoxicity in cultured embryonic spinal neurons. J Neurosci 13:2085-2104.

Vergun O, Keelan J, Khodorov BI, Duchen MR (1999) Glutamateinduced mitochondrial depolarisation and perturbation of calcium homeostasis in cultured rat hippocampal neurones. J Physiol (Lond) 519:451-466.

Vergun O, Han YY, Reynolds IJ (2003) Glucose deprivation produces a prolonged increase in sensitivity to glutamate in cultured rat cortical neurons. Exp Neurol 183:682-694.

Wang GJ, Thayer SA (1996) Sequestration of glutamate-induced Ca2+ loads by mitochondria in cultured rat hippocampal neurons. J Neurophysiol 76:1611-1621.

Ward MW, Rego AC, Frenguelli BG, Nicholls DG (2000) Mitochondrial membrane potential and glutamate excitotoxicity in cultured cerebellar granule cells. J Neurosci 20:7208-7219.
Ward MW, Kushnareva Y, Greenwood S, Connolly CN (2005) Cellular and subcellular calcium accumulation during glutamate-induced injury in cerebellar granule neurons. J Neurochem 92:1081-1090.

Ward MW, Rehm M, Duessmann H, Kacmar S, Concannon CG, Prehn JH (2006) Real time single cell analysis of Bid cleavage and Bid translocation during caspase-dependent and neuronal caspase-independent apoptosis. J Biol Chem 281:5837-5844.

White RJ, Reynolds IJ (1996) Mitochondrial depolarization in glutamatestimulated neurons: an early signal specific to excitotoxin exposure. J Neurosci 16:5688-5697.

White RJ, Reynolds IJ (1997) Mitochondria accumulate Ca2+ following intense glutamate stimulation of cultured rat forebrain neurones. J Physiol (Lond) 498:31-47.

Yang F, He XP, Russell J, Lu B (2003) Ca2+ influx-independent synaptic potentiation mediated by mitochondrial $\mathrm{Na}(+)-\mathrm{Ca} 2+$ exchanger and protein kinase C. J Cell Biol 163:511-523. 